\title{
The diagnosis of severe thunderstorms with high-resolution WRF model
}

\author{
A J Litta ${ }^{1,2, *}$, U C Mohantr ${ }^{1}$ and Sumam Mary Idicula ${ }^{2}$ \\ ${ }^{1}$ Centre for Atmospheric Sciences, Indian Institute of Technology, Delhi, Hauz Khas, New Delhi 110 016, India. \\ ${ }^{2}$ Department of Computer Science, Cochin University of Science and Technology, Cochin, Kerala 682 022, India. \\ ${ }^{*}$ Corresponding author.e-mail: littaaj@gmail.com
}

Thunderstorm, resulting from vigorous convective activity, is one of the most spectacular weather phenomena in the atmosphere. A common feature of the weather during the pre-monsoon season over the Indo-Gangetic Plain and northeast India is the outburst of severe local convective storms, commonly known as 'Nor'westers'(as they move from northwest to southeast). The severe thunderstorms associated with thunder, squall lines, lightning and hail cause extensive losses in agricultural, damage to structure and also loss of life. In this paper, sensitivity experiments have been conducted with the Non-hydrostatic Mesoscale Model (NMM) to test the impact of three microphysical schemes in capturing the severe thunderstorm event occurred over Kolkata on 15 May 2009. The results show that the WRF-NMM model with Ferrier microphysical scheme appears to reproduce the cloud and precipitation processes more realistically than other schemes. Also, we have made an attempt to diagnose four severe thunderstorms that occurred during pre-monsoon seasons of 2006, 2007 and 2008 through the simulated radar reflectivity fields from NMM model with Ferrier microphysics scheme and validated the model results with Kolkata Doppler Weather Radar (DWR) observations. Composite radar reflectivity simulated by WRF-NMM model clearly shows the severe thunderstorm movement as observed by DWR imageries, but failed to capture the intensity as in observations. The results of these analyses demonstrated the capability of high resolution WRF-NMM model in the simulation of severe thunderstorm events and determined that the $3 \mathrm{~km}$ model improve upon current abilities when it comes to simulating severe thunderstorms over east Indian region.

\section{Introduction}

Thunderstorms, which are mesoscale systems, are major cause of natural disasters during the pre-monsoon season (March-May). Many parts over the Indian region experience thunderstorms at higher frequency during that period, when the atmosphere is highly unstable because of high temperatures prevailing at lower levels. The 'Nor'westers' are severe thunderstorms that form and move from northwest to southeast over the eastern and northeastern states of India during the pre-monsoon season (figure 1). They are locally called 'Kalbaishakhi'. Strong heating of landmass during mid-day initiates convection over Chhotanagpur Plateau, which moves southeast and gets intensified by mixing with warm moist airmass. The Nor'westers produce heavy rain showers, lightning, thunder, hail-storms, dust-storms, surface wind squalls, down-bursts and occasionally tornadoes. The casualties reported due to lightning associated with thunderstorms in this region are the highest in the world. The strong wind produced by the thunderstorm is a real

Keywords. Mesoscale model; Nor'westers; thunderstorm; composite radar reflectivity; microphysics; cloud top temperature. 


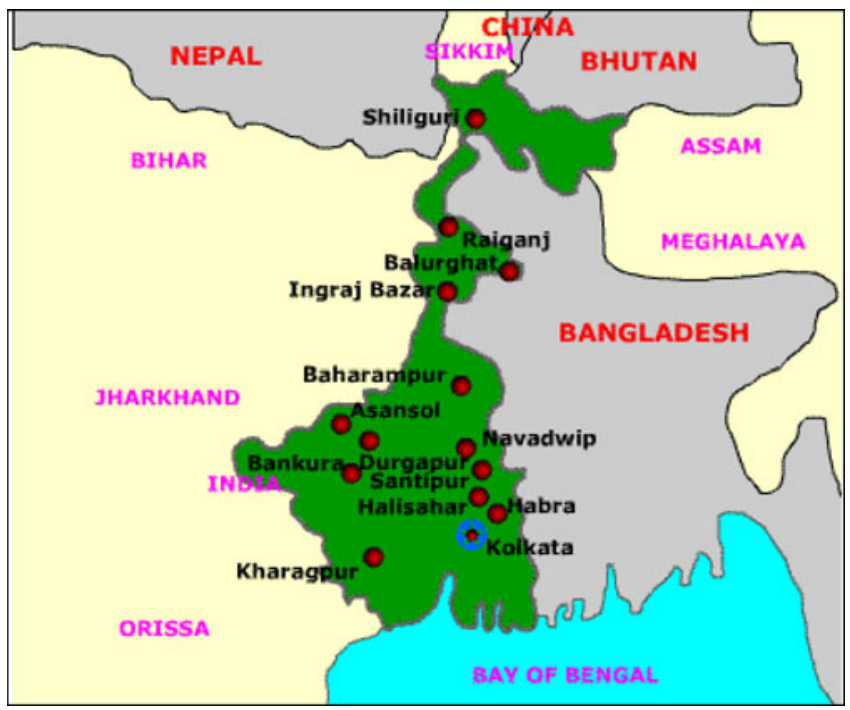

Figure 1. Geographical location of study area.

threat to aviation. The highest number of aviation hazards are reported during occurrence of these thunderstorms. In India, $72 \%$ of tornadoes are associated with Nor'westers (Science Plan 2005). These severe thunderstorms have significant socioeconomic impact in the eastern and northeastern parts of the country.

An accurate, location specific and timely prediction is required to avoid loss of lives and properties due to strong winds and heavy precipitation associated with such weather systems. Numerical modelling has made substantial advances in the modelling of convective clouds and mesoscale convective systems. Presently a large number of mesoscale models are available for simulation of the weather events at various scales. These models with unique combination of the multiple nesting capability, data assimilation techniques, several parameterization schemes for important physical processes options can be suitably customized for prediction of intense convective weather events like severe thunderstorms (Mohanty et al 2004). In India, studies related to modelling of clouds are very scarce and in particular, intense thunderstorm events (Das 1999). Simulation of active mesoscale systems such as tropical cyclones, heavy rainfall and severe thunderstorms with high-resolution mesoscale models has been attempted by many Indian researchers recently (e.g., Mohanty et al 2004; Litta et al 2007, 2010; Vaidya 2007; Litta and Mohanty 2008; Chatterjee et al 2008; Rajeevan et al 2010).

The use of Numerical Weather Prediction (NWP) output to complement the interpretation of conventional observations can add great value to the forecast process. The higher time and space resolution of the model data enables a forecaster to view the evolution of the weather situation in much greater detail and can provide an insightful framework within which actual observations can be interpreted. Contemporary atmospheric numerical models contain a large number of physical parameterization schemes in order to represent the various atmospheric processes that take place in sub-grid scales. However, modelling systems also reflect inherent errors and uncertainties in specifying the initial state of the atmosphere, and simplifications in physics and parameterization of subgrid scale processes further contribute to errors in model forecasts. It is believed that physics errors become more important as model resolution increases (e.g., Stensrud et al 2000; Wandishin et al 2001). The impact of cloud microphysics on cloud resolving simulations is an important issue in NWP and regional climate modelling. The sensitivity of cloud microphysics in predicting convective storms and precipitation has been addressed by many researchers (e.g., Liu and Moncrieff 2007; Rao et al 2007; Chatterjee et al 2008; Rajeevan et al 2010).

The use of composite radar reflectivity fields as a model output product has become increasingly popular as a means for displaying forecast fields from high resolution operational NWP models. In particular, plan view displays of composite radar reflectivity have become a common postprocessing output of both research and operational models. The reflectivity product offers significant advantages over traditional precipitation forecast displays, including the obvious fact that radar reflectivity is easier to verify by directly comparing with readily available, observed composite radar reflectivity products (Koch et al 2005). Another subtler advantage of the model reflectivity product is that it allows one to see more easily

Table 1. Summary of severe thunderstorm events used for the present study.

\begin{tabular}{lll}
\hline Sl. no. & \multicolumn{1}{c}{ Date } & \\
\hline 1 & 20 May 2006 & A squall passed over MO Kolkata on 20 May at 1100 UTC from northeasterly direction. \\
2 & 21 May 2007 & A squall passed over MO Kolkata on 21 May at 1100 UTC from northwesterly direction. \\
3 & 20 March 2008 & A squall passed over Kharagpur on 20 March at 1200 UTC from westerly direction. \\
4 & 8 May 2008 & A squall passed over MO Kolkata on 8 May at 1400 UTC from northwesterly direction. \\
5 & 15 May 2009 & A squall passed over MO Kolkata on 15 May 2009 at 1300 UTC from northwesterly direction. \\
\hline
\end{tabular}


Table 2. WRF-NMM model configuration.

\begin{tabular}{ll}
\hline Dynamics & \multicolumn{1}{c}{ Non-hydrostatic } \\
\hline Horizontal spatial resolution & $3 \mathrm{~km}$ \\
Integration time step & 6 seconds \\
Map projection & Rotated latitude and longitude \\
Horizontal grid system & Arakawa E-grid \\
Vertical co-ordinate & Terrain-following hybrid (sigma-pressure) \\
& vertical coordinate (38 sigma levels) \\
Radiation parameterization & GFDL/GFDL \\
Surface layer parameterization & Janjic similarity scheme \\
Land surface parameterization & NMM land surface scheme \\
Cumulus parameterization & Grell-Devenyi ensemble scheme \\
PBL parameterization & Mellor-Yamada-Janjic \\
\hline
\end{tabular}

the detailed mesoscale and near-stormscale structures capable of being forecast by finer resolution NWP models, such as the structure of deep convection, movement of squall line and frontal precipitation bands. Examples demonstrating this advantage for a variety of mesoscale phenomena observed during recent forecast experiments in the continental United States were presented by Koch et al (2005). Recently, installation Doppler Weather Radar (DWR) has highlighted the better prospect of mesoscale prediction in the nowcast to very short-range time scale over Indian region (eg., Sen Roy et al 2010; Srivastava et al 2010).

In this paper, sensitivity experiments have been conducted with the NMM model to examine the impact of three microphysical schemes in capturing the severe thunderstorm event occurred over Kolkata on 15 May 2009. Also, we have made an attempt to diagnose four severe thunderstorms that occurred during pre-monsoon seasons of 2006, 2007 and 2008 through the simulated radar reflectivity fields from NMM model with Ferrier microphysics scheme and validated the model results with Kolkata DWR observations. The goal of this study is to determine the usefulness of high resolution WRF-NMM model when it comes to the severe thunderstorm simulation over east and northeast region of India. Table 1 summarizes the severe thunderstorm events used for the present study. This paper is presented in the following manner. Section 2 gives a brief description of numerical model and configuration, section 3 gives results and discussion and section 4 conclusions.

\section{Numerical model}

The NMM core of the Weather Research and Forecasting (WRF) system is a next-generation mesoscale forecast model that will be used to advance the understanding and the prediction of mesoscale convective systems. The model was developed by the National Oceanic and Atmospheric Administration (NOAA)/National Centers for Environment Prediction (NCEP). The WRFNMM model has been designed to be an efficient

Table 3. NMM model simulated stability indices over Kolkata between 1000 and 1300 UTC for different microphysics scheme on 15 May 2009.

\begin{tabular}{|c|c|c|c|c|c|c|c|c|}
\hline Stability indices & Description & $\begin{array}{l}\text { Critical } \\
\text { level }\end{array}$ & $\begin{array}{l}\text { Thunder } \\
\text { storm cases }\end{array}$ & $\begin{array}{l}1000 \\
\text { UTC }\end{array}$ & $\begin{array}{l}1100 \\
\text { UTC }\end{array}$ & $\begin{array}{l}1200 \\
\text { UTC }\end{array}$ & $\begin{array}{l}1300 \\
\text { UTC }\end{array}$ & Average \\
\hline \multirow[t]{3}{*}{ CAPE } & \multirow[t]{3}{*}{$\int_{z_{f}}^{z_{n}} g\left(\frac{T v_{\text {parcel }}-T v_{\text {env }}}{T v_{\text {env }}}\right) d z$} & \multirow[t]{3}{*}{$>1500$} & FERR & 2576 & 3261 & 2993 & 2428 & 2815 \\
\hline & & & WSM6 & 2114 & 3287 & 3032 & 2664 & 2774 \\
\hline & & & THOM & 2123 & 3520 & 3012 & 2603 & 2815 \\
\hline \multirow[t]{3}{*}{ Lifted index (LI) } & \multirow[t]{3}{*}{$\mathrm{T}_{500}-\mathrm{T}_{\text {parcel }}$} & \multirow[t]{3}{*}{$<-3$} & FERR & -5 & -6 & -6 & -6 & -6 \\
\hline & & & WSM6 & -4 & -6 & -6 & -6 & -6 \\
\hline & & & THOM & -4 & -6 & -6 & -6 & -6 \\
\hline \multirow[t]{3}{*}{$\mathrm{K}$ index $(\mathrm{KI})$} & \multirow{3}{*}{$\begin{array}{l}\left(\mathrm{T}_{850}-\mathrm{T}_{500}\right)+\mathrm{Td}_{850} \\
\quad-\left(\mathrm{T}_{700}-\mathrm{DT}_{700}\right)\end{array}$} & \multirow[t]{3}{*}{$>33$} & FERR & 32 & 31 & 31 & 31 & 31 \\
\hline & & & WSM6 & 29 & 24 & 27 & 27 & 27 \\
\hline & & & THOM & 29 & 25 & 27 & 25 & 27 \\
\hline \multirow[t]{3}{*}{ Total Total index (TTI) } & \multirow[t]{3}{*}{$\left(\mathrm{T}_{850}+\mathrm{Td}_{850}\right)-2\left(\mathrm{~T}_{500}\right)$} & \multirow[t]{3}{*}{$>44$} & FERR & 46 & 46 & 45 & 46 & 46 \\
\hline & & & WSM6 & 46 & 42 & 45 & 46 & 45 \\
\hline & & & THOM & 46 & 43 & 45 & 45 & 45 \\
\hline
\end{tabular}


a) TRMM

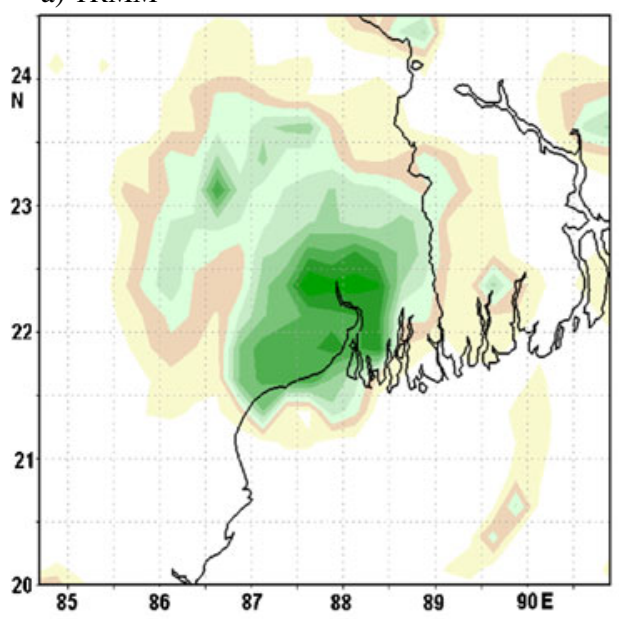

c) WSM6

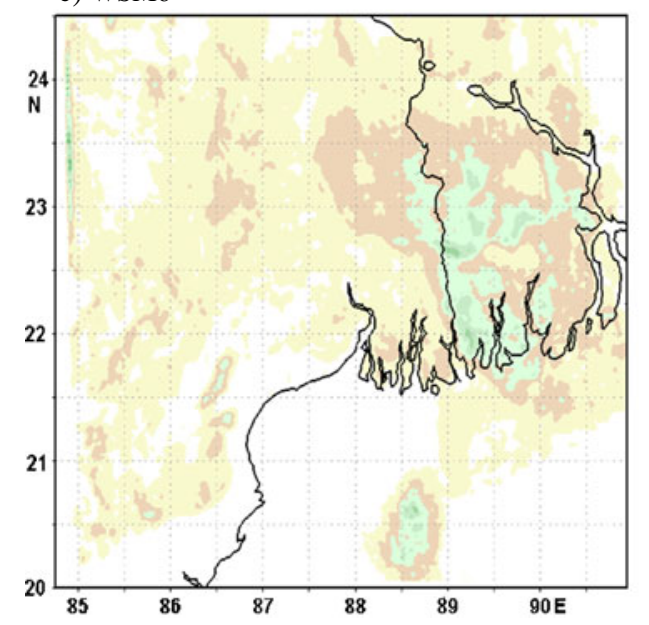

b) FERR

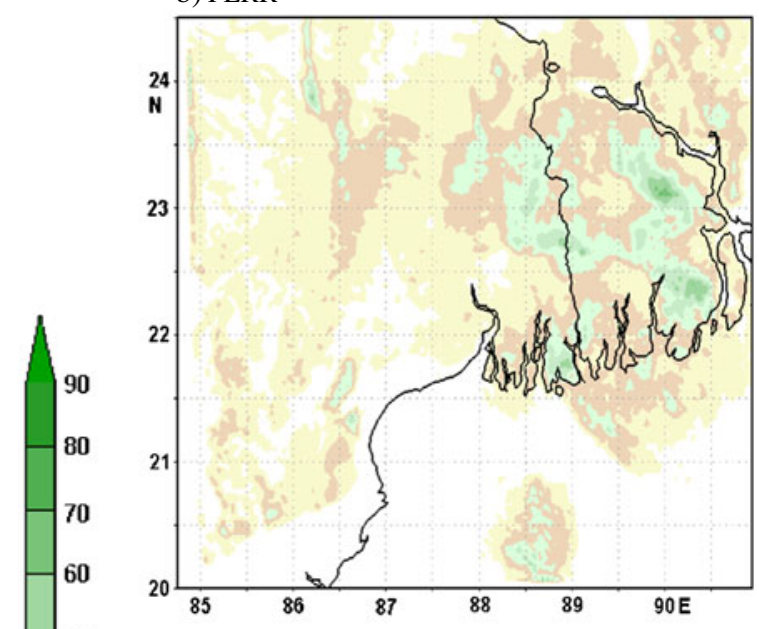

d) THOM

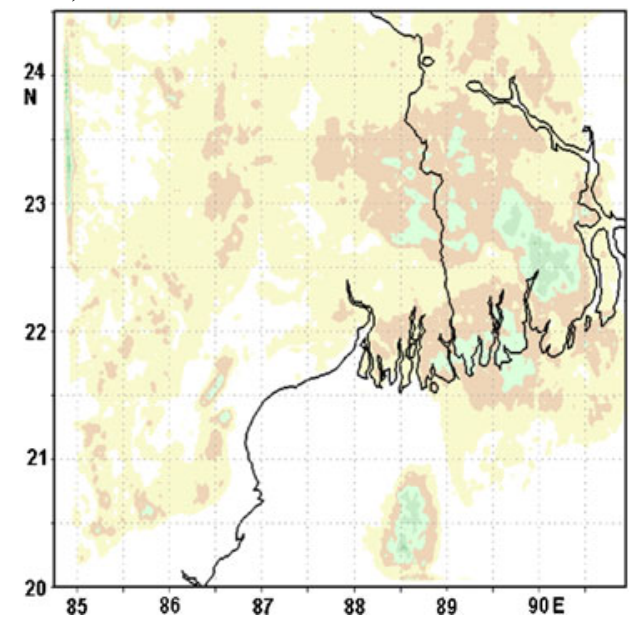

Figure 2. Comparison of TRMM and NMM model simulated $24 \mathrm{~h}$ accumulated rainfall (mm) with three microphysics scheme on 15 May 2009 (a) TRMM, (b) FERR, (c) WSM6 and (d) THOM.

and flexible mesoscale modelling system for use across a broad range of weather forecast and idealized research applications, with an emphasis on horizontal grid sizes in the range of 1-10 km. This model can resolve the small-scale weather features such as front, localized convection, hurricane core and topographic effect much better than the global model. Several studies related to the simulation of severe thunderstorm events using NMM model have been performed (Kain et al 2006;
Szoke et al 2007; Litta and Mohanty 2008; Litta et al 2010).

The WRF-NMM is a fully compressible, nonhydrostatic mesoscale model with a hydrostatic option (Janjic 2003). The model uses a terrain following hybrid sigma-pressure vertical coordinate. The grid staggering is the Arakawa E-grid. The model uses a forward-backward scheme for horizontally propagating fast waves, implicit scheme for vertically propagating sound waves, Adams-

Table 4. Comparison of the $24 \mathrm{~h}$ accumulated precipitation $(\mathrm{mm})$ for six meteorological stations from NMM model with different microphysics schemes and satellite and ground based observations.

\begin{tabular}{llllccc}
\hline Station & Lat. & Long. & OBS & TRMM & FERR & WSM6 \\
\hline Dum Dum & 22.39 & 88.27 & 16.9 & 53 & 17.2 & 10.78 \\
Bankura & 23.13 & 87.04 & 34 & 52.4 & 14.7 & 15.32 \\
Krishnagar & 23.24 & 88.31 & 19.6 & 21.1 & 18.7 & 25.81 \\
Digha & 21.5 & 87.48 & 21 & 79.4 & 18.4 & 10 \\
Midnapore & 22.25 & 87.19 & 51.6 & 69.4 & 26.5 & 12.65 \\
Haldia & 22.04 & 88.04 & 33.2 & 79.1 & 30.4 & 15.71 \\
\hline
\end{tabular}


Table 5. Analysis of modelled and TRMM precipitation with IMD observations using statistical methods.

\begin{tabular}{lcccc}
\hline Statistical analysis & TRMM & FERR & WSM6 & THOM \\
\hline $\begin{array}{c}\text { Root mean square } \\
\text { error (RMSE) }\end{array}$ & 35.304 & 13.026 & 19.870 & 18.911 \\
$\begin{array}{c}\text { Mean absolute } \\
\text { error (MAE) }\end{array}$ & 29.683 & 8.5 & 16.408 & 15.005 \\
\begin{tabular}{l} 
Mean error (ME) \\
\hline
\end{tabular} & -29.683 & 8.4 & 14.338 & 14.088 \\
\hline
\end{tabular}

Bashforth scheme for horizontal advection, and Crank-Nicholson scheme for vertical advection. The same time step is used for all terms. The dynamics conserve a number of first and second order quantities including energy and enstrophy (Janjic 1984).
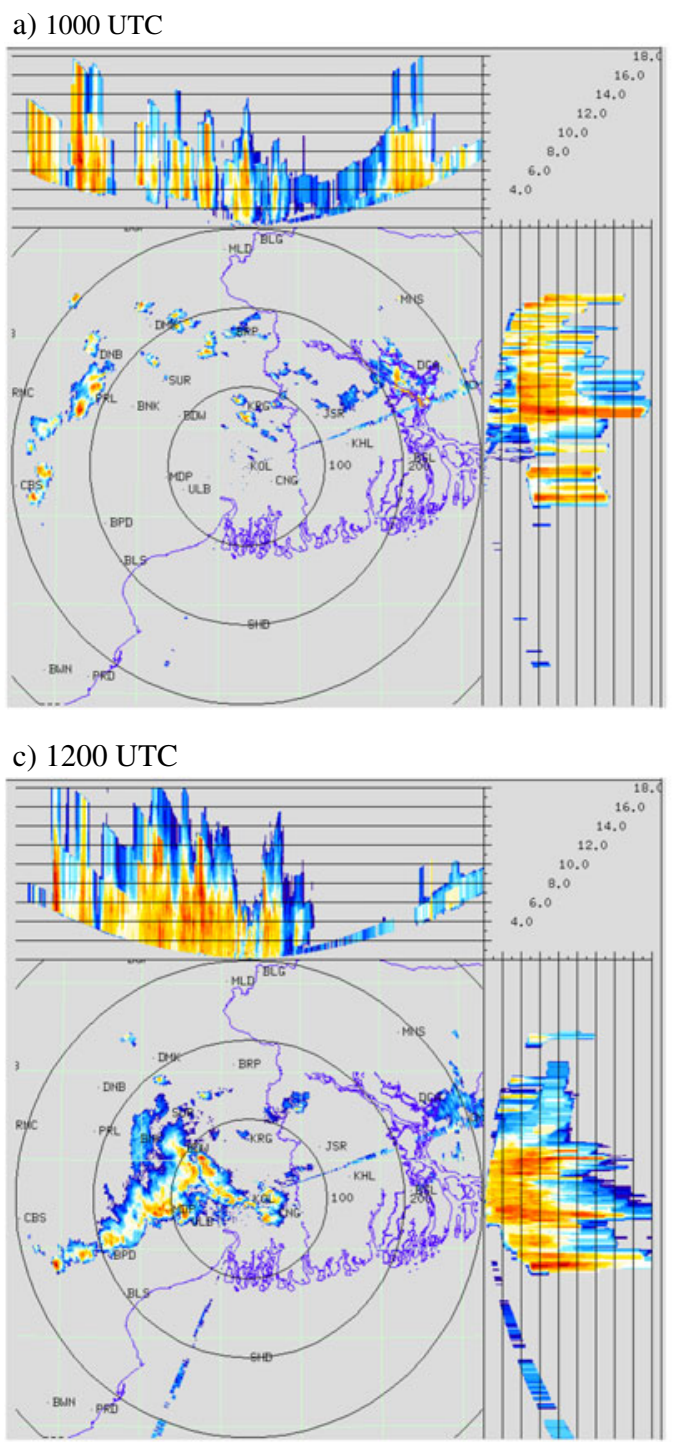

In the present simulation study, the model was integrated for a period of 24 hours. A single domain with $3 \mathrm{~km}$ horizontal spatial resolution was configured. Initial conditions for the $3 \mathrm{~km}$ domain are derived from 6 -h global final analysis (FNL) at $1.0^{\circ} \times 1.0^{\circ}$ grids generated by National Center for Environmental Prediction (NCEP)'s Global Forecast System (GFS). Analysis fields, including temperature, moisture, geopotential height and wind, are interpolated to the mesoscale grids by the WRF preprocessing systems (WPS). These derived fields served as initial conditions for the present experiments. The domain is configured with vertical structure of 38 unequally spaced sigma (non-dimensional pressure) levels. The physical parameterizations used in this study are Geophysical Fluid Dynamics Laboratory (GFDL) for radiation,
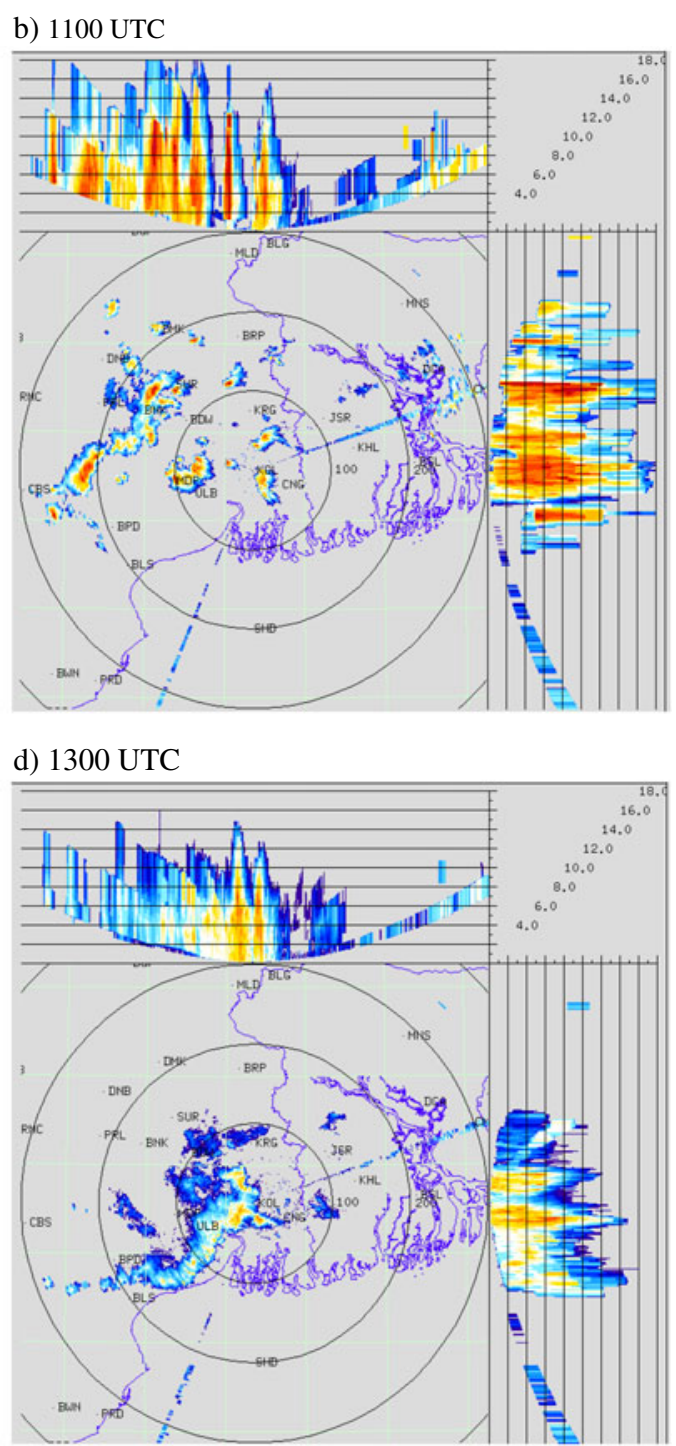

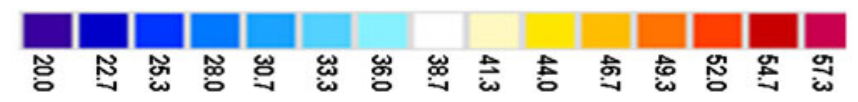

Figure 3. Kolkata DWR composite radar reflectivity (dBZ) imageries from 1000 to 1300 UTC on 15 May 2009. 
NMM land surface scheme for land surface, Mellor Yamada Janjic (MYJ) scheme for planetary boundary layer, Janjic similarity scheme for surface layer and Grell-Devenyi cloud ensemble scheme for cumulus parameterization.

The simulations from numerical models are known to be sensitive to the representation of the physical processes. The microphysics schemes vary in complexity from relatively simple single-moment schemes that explicitly predict the mixing ratio of each hydrometeor species to a more sophisticated double-moment scheme that predicts both the mixing ratio and number concentration. Each microphysics scheme contains prognostic equations describing the evolution of six hydrometeor species (water vapour, cloud water, rainwater, ice, snow and graupel) (Otkin and Greenwald 2008). Sensitivity experiments have been conducted for a severe thunderstorm event on 15 May 2009 with three microphysical schemes namely
Ferrier (FERR) (Ferrier et al 2002), WRF Single Moment 6 class (WSM6) (Hong et al 2004) and Thomson scheme (THOM) (Thompson et al 2004). In all experiments, the model setups were identical except for the use of different microphysics schemes. The model results are analyzed and compared to the available surface observations and satellite derived data in order to identify the parameterizations that provide the best representation of the spatio-temporal variability of thunderstorm affected parameters. Table 2 shows the model configuration for the present study.

\section{Results and discussion}

Today there are a number of parameters available that may be used to characterize pre-convective conditions and predict the beginning of convection. Simulated thunderstorm properties have been a) 1000 UTC

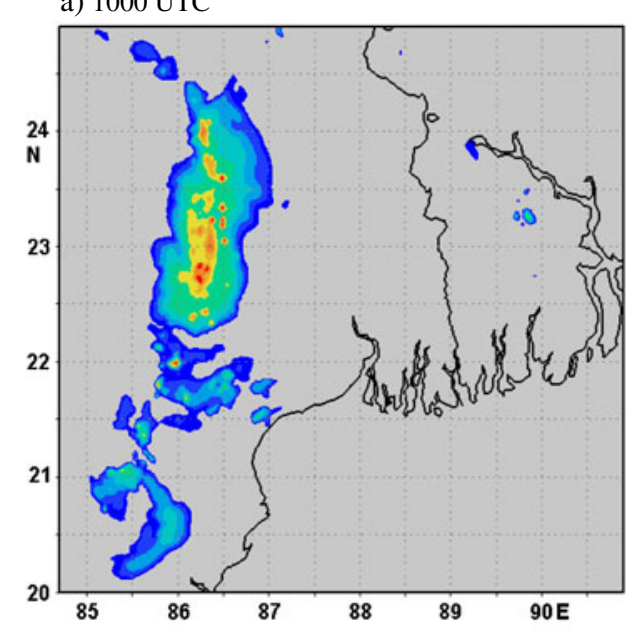

c) 1200 UTC

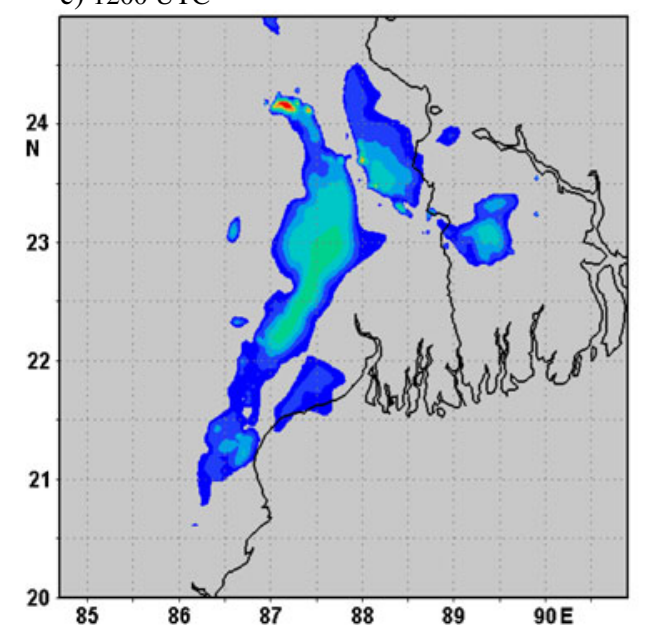

b) $1100 \mathrm{UTC}$

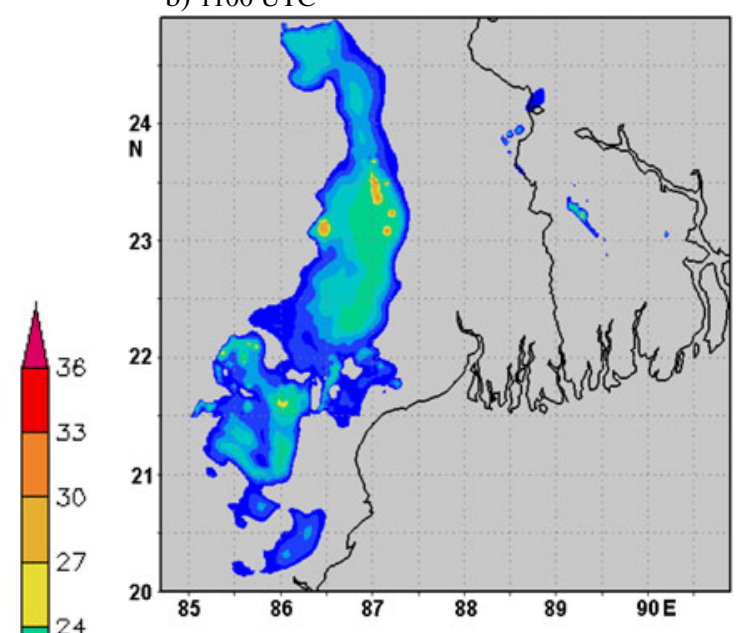

d) 1300 UTC

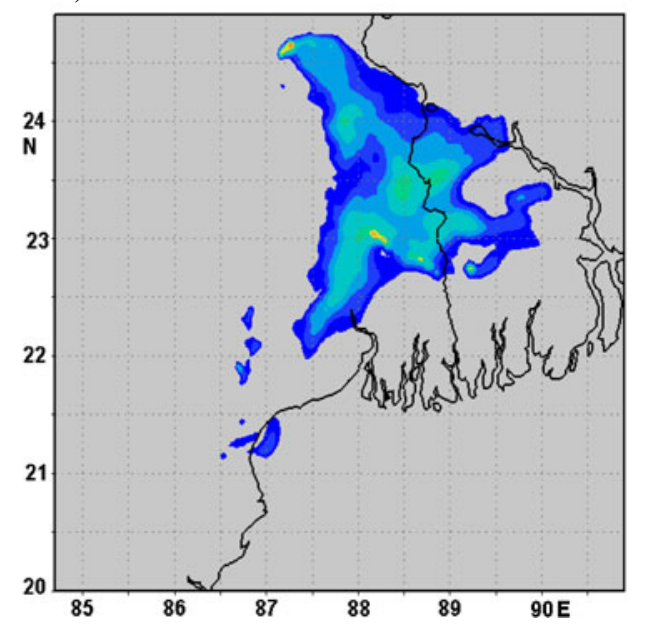

Figure 4. (a) WRF-NMM simulated composite radar reflectivity (dBZ) pictures from 1000 to 1300 UTC on 15 May 2009 using FERR microphysics scheme. 
evaluated in this section by simulated stability indices, simulated surface precipitation, simulated radar reflectivity and simulated cloud top temperature with three microphysics schemes implemented in the WRF-NMM model. Analysis of the results of these experiments is helpful to understand the impact of microphysics schemes on the simulation of 15 May 2009 severe thunderstorm event and assist in the customization of model for other severe thunderstorm simulations over east Indian region during 2006, 2007 and 2008.

\subsection{Sensitivity experiments with three microphysics schemes}

\subsubsection{Details of the thunderstorm}

The severe thunderstorm event examined here occurred over east India during the evening of 15 May 2009. The convective formation was realized at several stations over West Bengal, squalls also passed and rainfall was recorded in a general sense.
Realized weather over east region is as follows: A squall passed over Bankura $\left(23.13^{\circ} \mathrm{N}, 87.04^{\circ} \mathrm{E}\right)$ at 1200 UTC from westerly direction with maximum speed of $30.2 \mathrm{kts}\left(15.6 \mathrm{~ms}^{-1}\right)$. This intense convective event produced $34.0 \mathrm{~mm}$ rainfall over Bankura. A squall passed over Digha $\left(21.5^{\circ} \mathrm{N}\right.$, $87.48^{\circ} \mathrm{E}$ ) at $1300 \mathrm{UTC}$ from northwesterly direction with maximum speed of $36.2 \mathrm{kts}\left(18.6 \mathrm{~ms}^{-1}\right)$ and produced $21.0 \mathrm{~mm}$ rainfall. A squall passed over Dum Dum (Kolkata) with a maximum speed of $37 \mathrm{kts}\left(18.9 \mathrm{~ms}^{-1}\right)$ lasting for a few minutes and produced $16.9 \mathrm{~mm}$ rainfall. A few places recorded moderate rainfall over GWB and isolated rainfall over Orissa, Jharkhand and Bihar. Haldia recorded $33.2 \mathrm{~mm}$ and Midnapore $51.6 \mathrm{~mm}$ of rainfall. For this event, synoptic chart analysis shows that a cyclonic circulation exists in lower levels over west Uttar Pradesh. A trough from this system extends up to Nagaland across Bihar and GWB. Incursion of moisture is taking place over east and northeast India due to westerly jets. Satellite pictures showed a large cloud cluster centred over West Bengal a) $1000 \mathrm{UTC}$

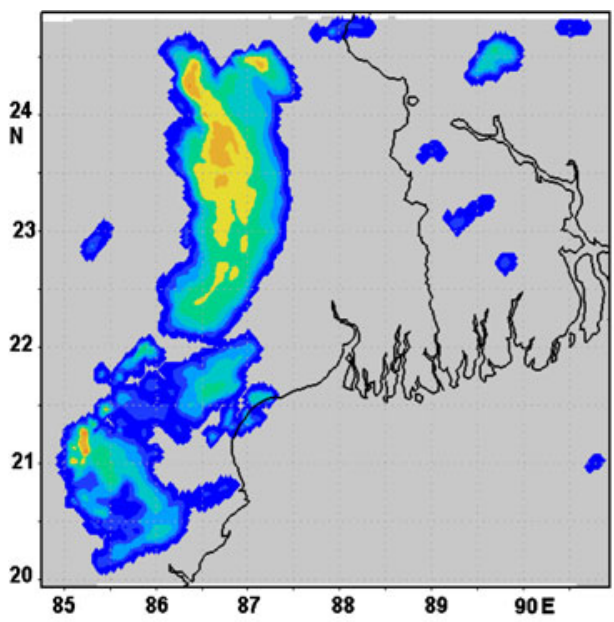

c) 1200 UTC

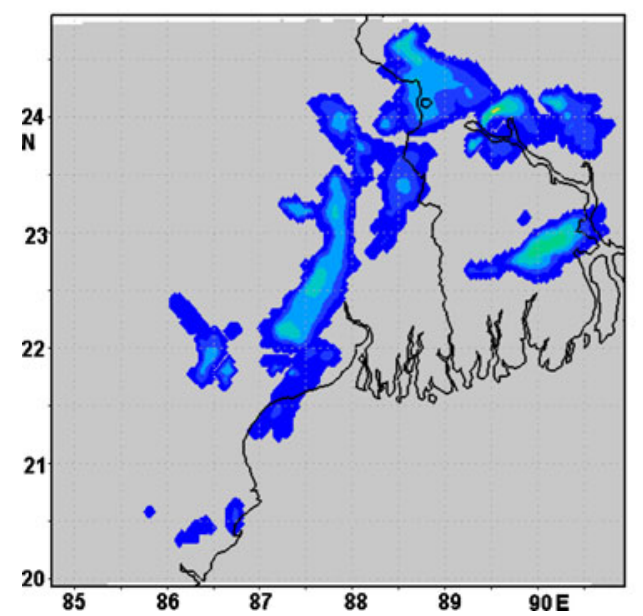

b) $1100 \mathrm{UTC}$

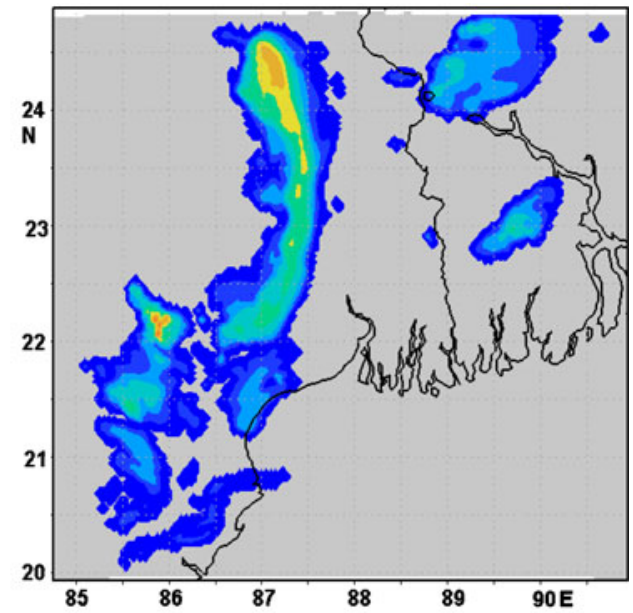

d) $1300 \mathrm{UTC}$

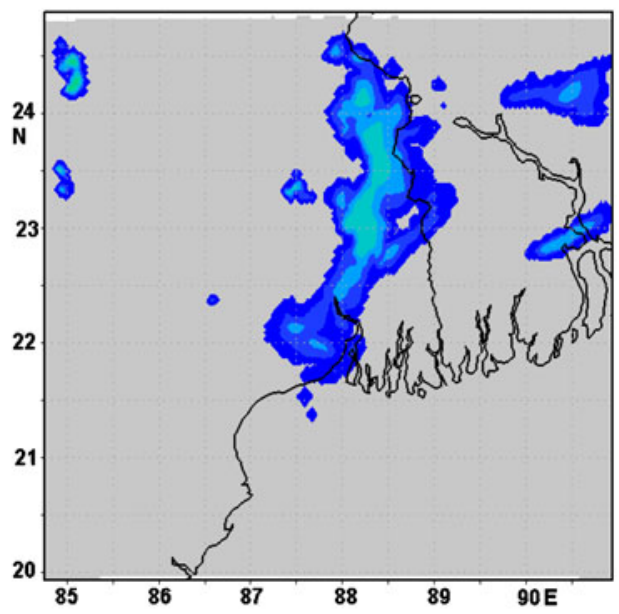

Figure 4. (b) Same as figure 4(a) except using WSM6 microphysics scheme. 
region. Kolkata radar showed deep convection at 1200 UTC (Mohanty et al 2009).

\subsubsection{Instability indicators from the model}

Variation of convection in the atmosphere depends upon dynamics as well as thermodynamic instability indices. A number of stability indices are devised in order to detect the likely occurrence of thunderstorms. An attempt is made to examine different stability indices namely Convective Available Potential Energy (CAPE), Lifted Index (LI), Total Total Index (TTI) and K Index (KI) obtained from NMM model during this severe local storm day over Kolkata $\left(22.65^{\circ} \mathrm{N}, 88.45^{\circ} \mathrm{E}\right)$. The model results are not able to compare with observed stability indices at Kolkata due to unavailability of observed data. Due to certain consumable problem, there was no radiosonde ascent in Kolkata station at 1200 UTC on 15 May 2009 during the SAARC STORM field experiment 2009. Table 3 shows the
NMM model simulated stability indices with three microphysics schemes (FERR, WSM6 and THOM) over Kolkata between 1000 and 1300 UTC on 15 May 2009. The CAPE represents the amount of buoyant energy available to accelerate a parcel vertically and a CAPE value greater than $1500 \mathrm{Jkg}^{-1}$ is suggested by Johns and Doswell (1992) as being necessary for supercells to form. The NMM model simulated CAPE values with different microphysics schemes are high and greater than the critical level during this thunderstorm life cycle. Average CAPE values for all microphysics schemes are greater than $2500 \mathrm{Jkg}^{-1}$ (table 3), which is a favourable condition for severe thunderstorm occurrence.

The LI measures the difference between a parcel's temperatures and the environmental temperature at $500 \mathrm{hPa}$, after the parcel has been lifted from the Lifting Condensation Level (Air Weather Service (AWS) Technical Report 1990). The LI has proved useful for indicating the likelihood of severe thunderstorms. The chances of a severe thunderstorm are best when the LI is less than or equal to

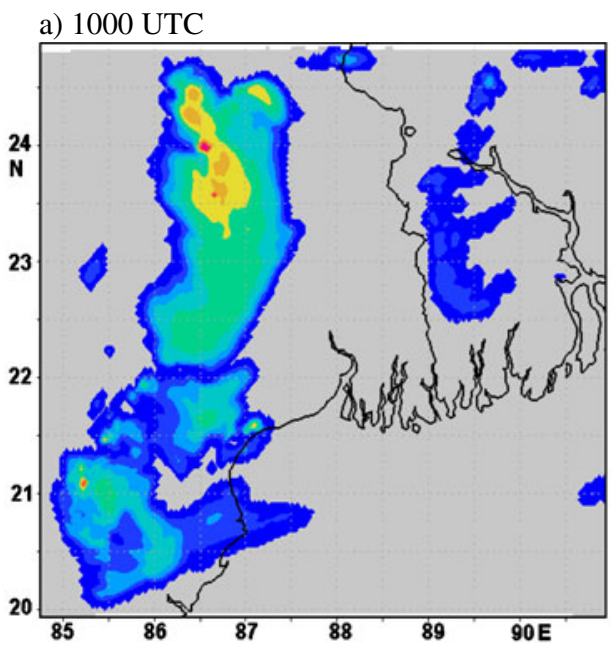

\section{b) 1100 UTC}

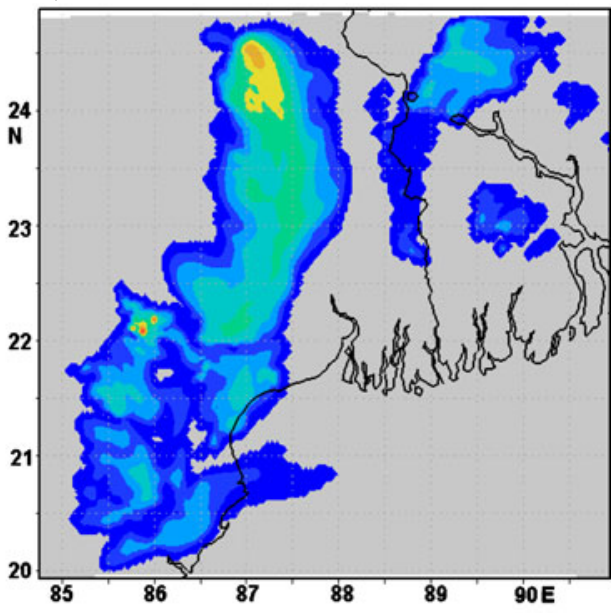

d) 1300 UTC

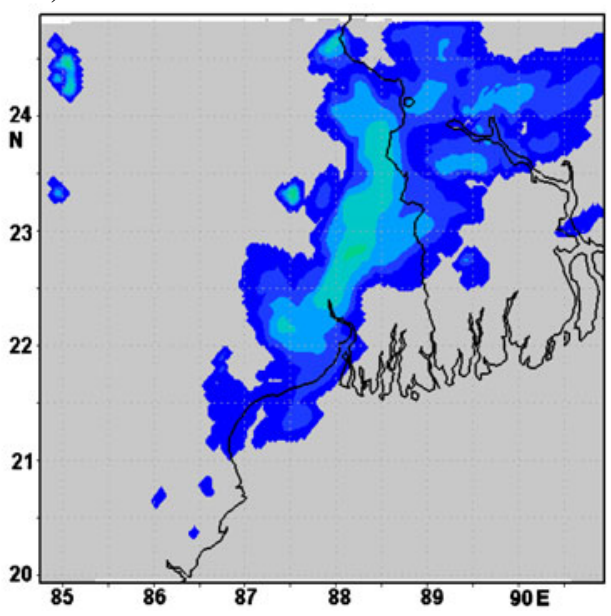

Figure 4. (c) Same as figure 4(a) except using THOM microphysics scheme. 
-3 . This is because air rising in these situations is much warmer than its surroundings and can accelerate rapidly and create tall and violent thunderstorms. The NMM model simulated LI values are very less during 1100 and 1300 UTC. The average value of model simulated LI with different microphysics scheme is -6 , which is less than the critical level and favourable for thunderstorm occurrences.

The KI is a combination of the Vertical Totals (VT) and lower tropospheric moisture characteristics. The VT is the temperature difference between 850 and $500 \mathrm{hPa}$, while the moisture parameters are $850 \mathrm{hPa}$ dewpoint and $700 \mathrm{hPa}$ dewpoint depressions. The KI has proved useful in indicating the probability of severe thunderstorms. As the KI increases, so does the probability of having a severe thunderstorm (AWS Technical Report 1990). The model simulated KI value with FERR scheme is close to the critical level during the thunderstorm hours. The average KI value of FERR scheme is 31 which is favourable for thunderstorm occurrence. The KI value of WSM6 and THOM schemes are very less than the critical level. The model simulated average KI value with WSM6 and THOM is 27 and which is not a good value for the thunderstorm occurrence (table 3). Miller (1972) introduced the TTI for identifying areas of potential thunderstorm development. It accounts for both static stability and the presence of $850 \mathrm{hPa}$ moisture. A TTI of greater than 44 indicates favourable conditions for the development of severe thunderstorms (AWS Technical Report 1990). The model simulated TTI with different microphysics schemes are showing high values, which is greater than 44 during the thunderstorm hours of these severe local storm (table 3). Examination of all the model simulated stability indices between 1000 and 1300 UTC of 15 May 2009, clearly indicated that NMM model with FERR microphysics scheme has well captured the instability of the atmosphere for the occurrence of a severe thunderstorm. The model simulated thermodynamic structure over Kolkata was conducive for a thunderstorm occurrence. CAPE, LI and TTI are well simulated by the other a) $1000 \mathrm{UTC}$

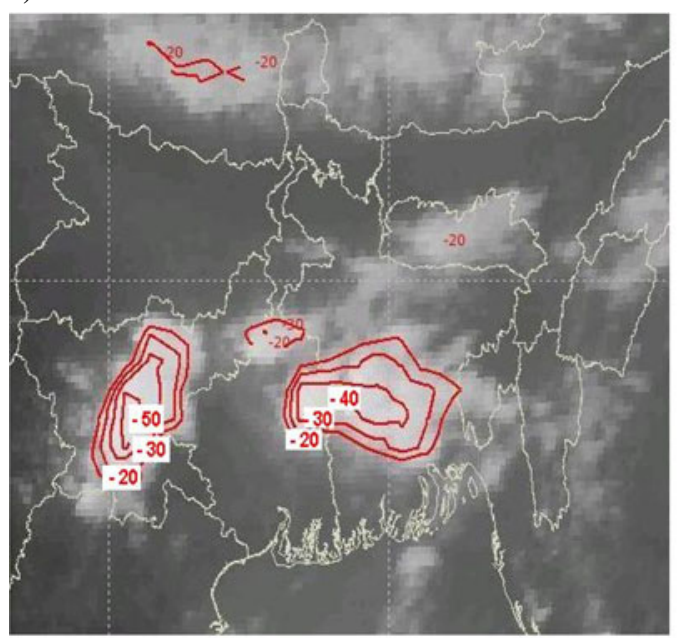

c) 1200 UTC

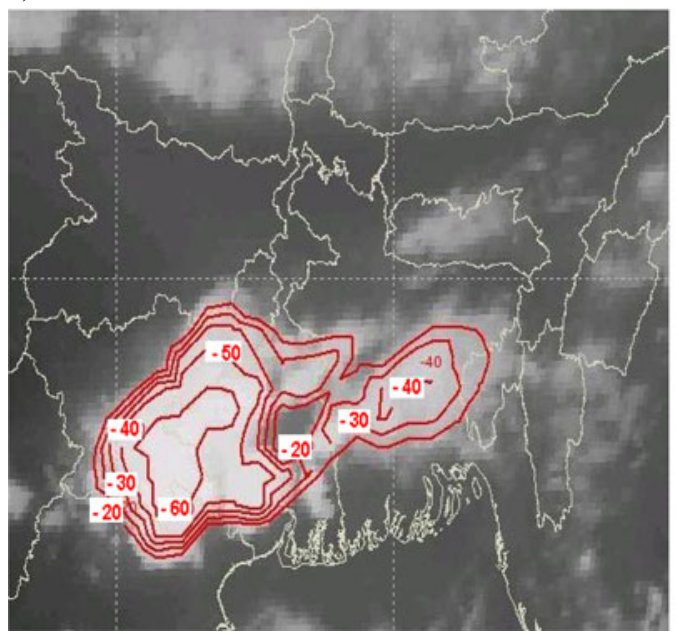

b) $1100 \mathrm{UTC}$

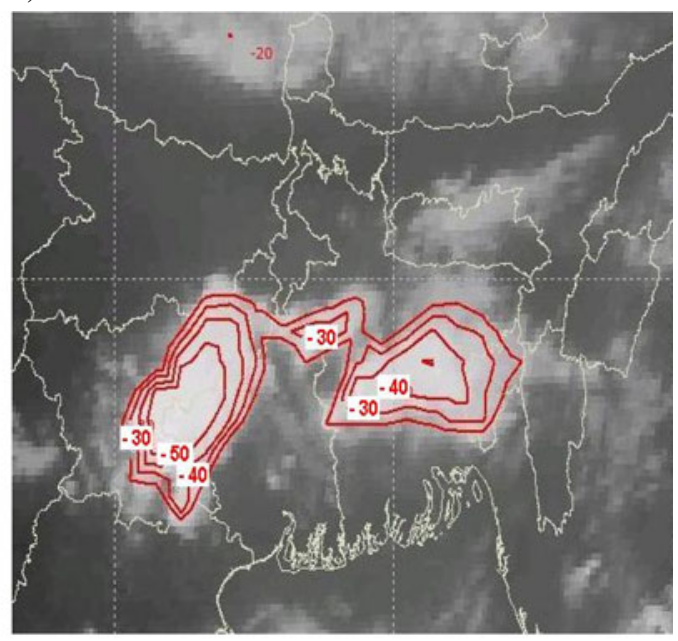

d) 1300 UTC

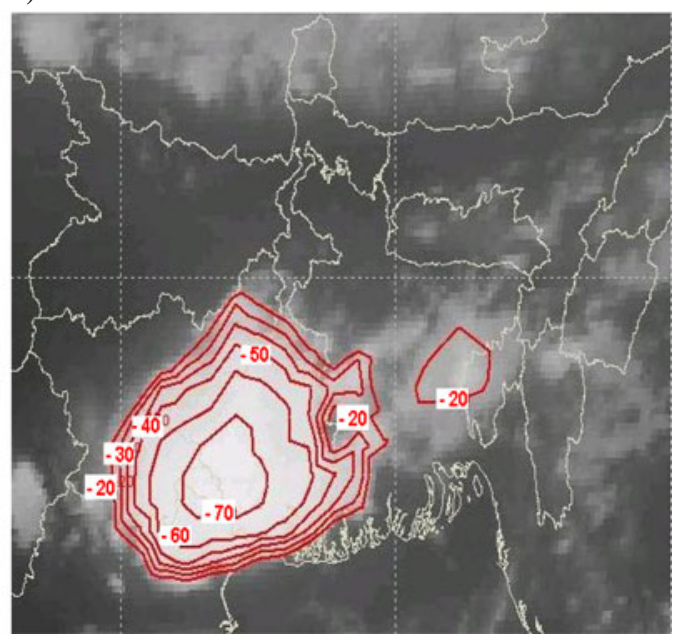

Figure 5. Kalpana satellite derived cloud top temperature $\left({ }^{\circ} \mathrm{C}\right)$ imageries from 1000 to 1300 UTC on 15 May 2009. 
microphysical schemes also. They are failed to produce an accurate value of KI index.

\subsubsection{Analysis of modelled precipitation}

Precipitation is recognized as one of the most difficult parameters to forecast in numerical weather prediction despite the fact that the accuracy of numerical models has increased during the past several decades (Wang and Seaman 1997). Accurate estimates of precipitation at both high temporal and spatial resolutions are required for many applications. In this section, a quantitative assessment of model simulated rainfall data using different microphysics schemes and surface rain gauge observations of the India Meteorological Department (IMD) and TRMM 3B42V6 product over east Indian region on 15 May 2009 has been presented.

The Tropical Rainfall Measuring Mission (TRMM) provides precipitation estimates at fine spatial scales using a calibration based sequential scheme and data from multiple satellites as well as rain gauge analysis. As the standard TRMM product, the Multi-satellite Precipitation Analysis (TMPA) not only provides a near real-time 3B42RT data but also a research-quality 3B42V6 rainfall dataset. In this study, the $3 \mathrm{~B} 42$ version 6 product of TRMM is used. This is a product spanning global belt from $50^{\circ} \mathrm{N}$ to $50^{\circ} \mathrm{S}$ with spatial resolution of $0.25^{\circ} \times 0.25^{\circ}$, with outputs at $3-\mathrm{h}$ interval. The four steps algorithm estimates precipitation with a combination of passive microwave sensors calibrated with infrared (IR) estimates to provide the best adjustment at each grid box, and finally rescales the 3-hourly product to the monthly dataset, indirectly using rain gauge data to perform a bias correction (Huffman et al 2007). The precipitation is accumulated in $24 \mathrm{~h}$, starting from 0000 UTC of the day and ending at 0000 UTC of the following day. The comparison of $24 \mathrm{~h}$ accumulated TRMM and NMM model simulated rainfall with three different microphysics schemes on 15 May 2009 is plotted in figure 2. Prior a) 1000 UTC

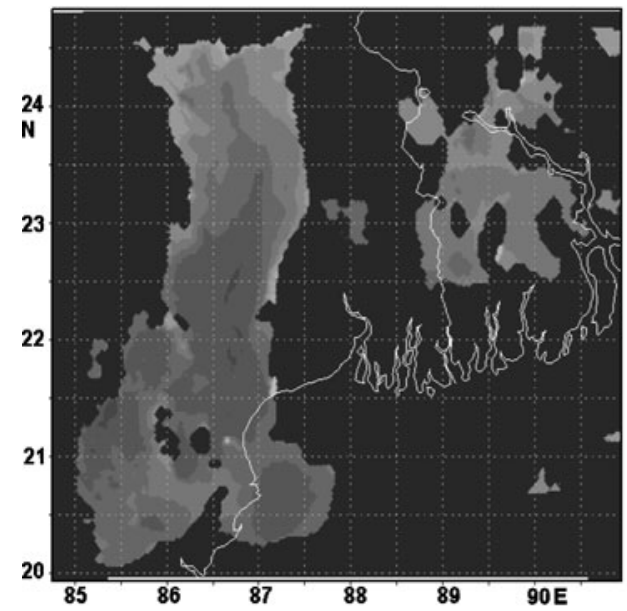

c) 1200 UTC

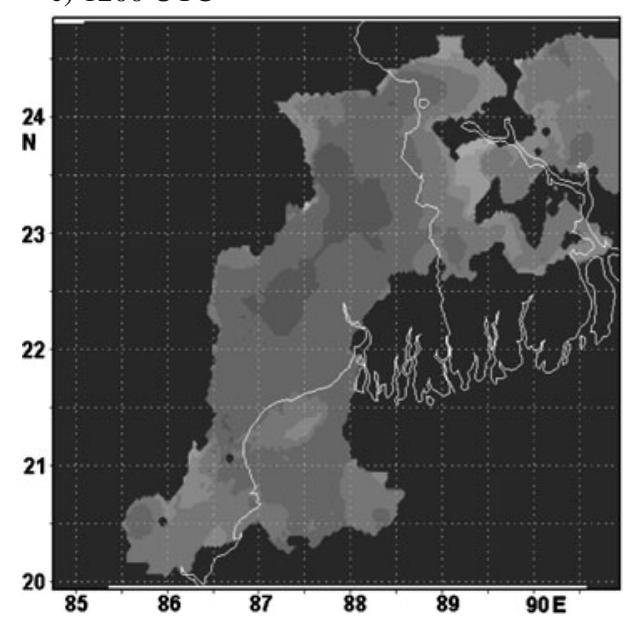

\section{b) 1100 UTC}

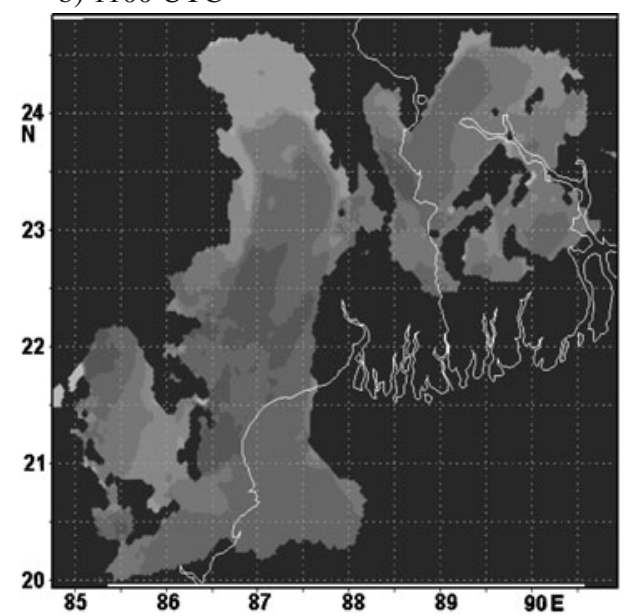

d) 1300 UTC

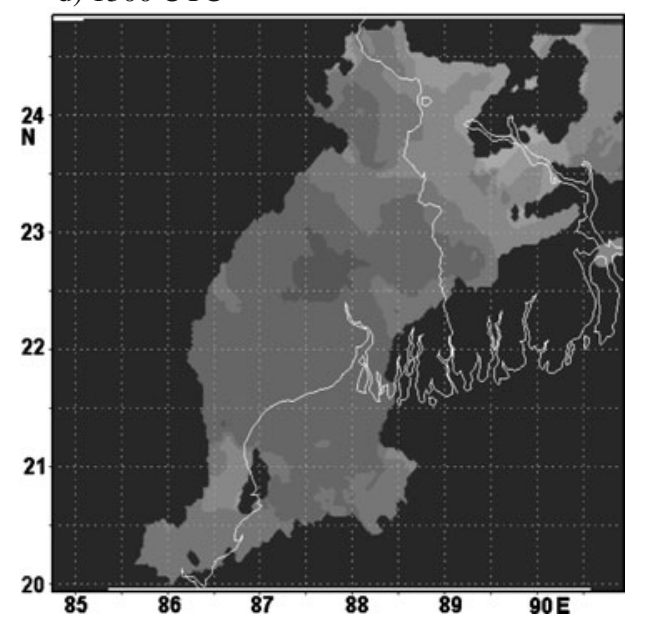

Figure 6. WRF-NMM model simulated cloud top temperature $\left({ }^{\circ} \mathrm{C}\right)$ from 1000 to 1300 UTC using FERR microphysics scheme. 
studies have shown that a model's microphysical parameterization scheme can strongly influence the magnitude of predicted precipitation (Otkin et al 2006). The overall rainfall distribution is reasonably well captured by the NMM model with FERR scheme than THOM and WSM6 schemes. The maximum intensity of model simulated rainfall with FERR scheme is $60-70 \mathrm{~mm}$ whereas the TRMM rainfall intensity is $80-90 \mathrm{~mm}$. But the other two parameterization schemes are failed to capture this maximum intensity over West Bengal Region. FERR scheme shows a rainfall spread in the range of 20-50 $\mathrm{mm}$ over northwest and northeast of Kolkata as in TRMM plot. The NMM model plots with all microphysics schemes showed a high spell of rainfall over southwest Bangladesh as in the TRMM rainfall plot.

a) 0900 UTC

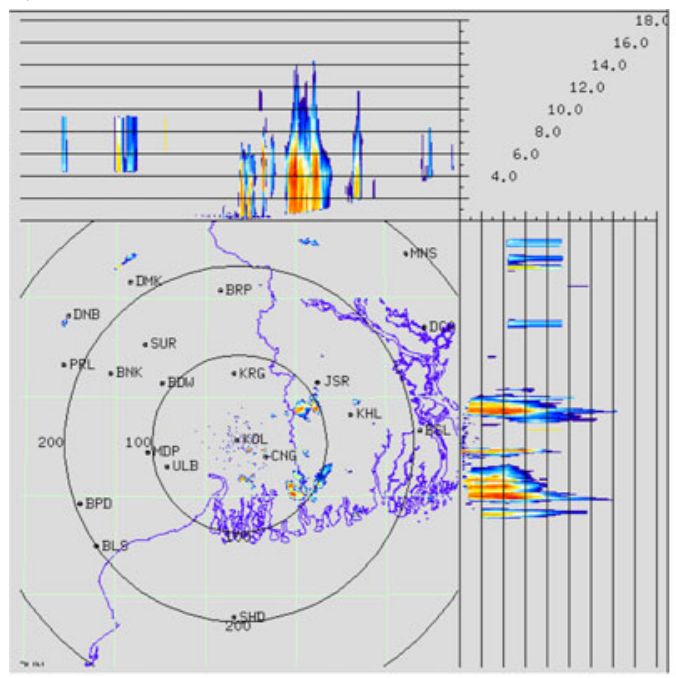

c) $1100 \mathrm{UTC}$

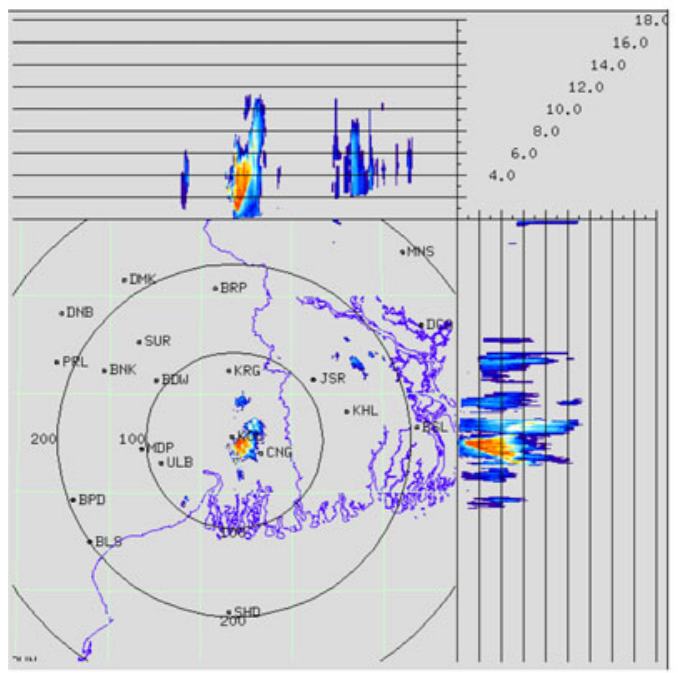

Table 4 shows the comparison of 24 -h accumulated precipitations over six meteorological stations over West Bengal Region from TRMM product, NMM model with three microphysics schemes and rain gauge observations. The results suggest an overall improvement from NMM model with FERR scheme over TRMM with respect to groundbased measurements. In all the cases, FERR was closer to the records while TRMM overestimated the amounts. Haldia reported $33.2 \mathrm{~mm}$ rainfall whereas TRMM estimated rainfall at Haldia is $79.1 \mathrm{~mm}$. While FERR scheme estimated $30.1 \mathrm{~mm}$ over Haldia which is close to the IMD observation. The other two microphysics schemes have underestimated the rainfall amount over all five stations as in the spatial rainfall distribution. The three datasets are closely agreed at Krishnagar

\section{b) 1000 UTC}

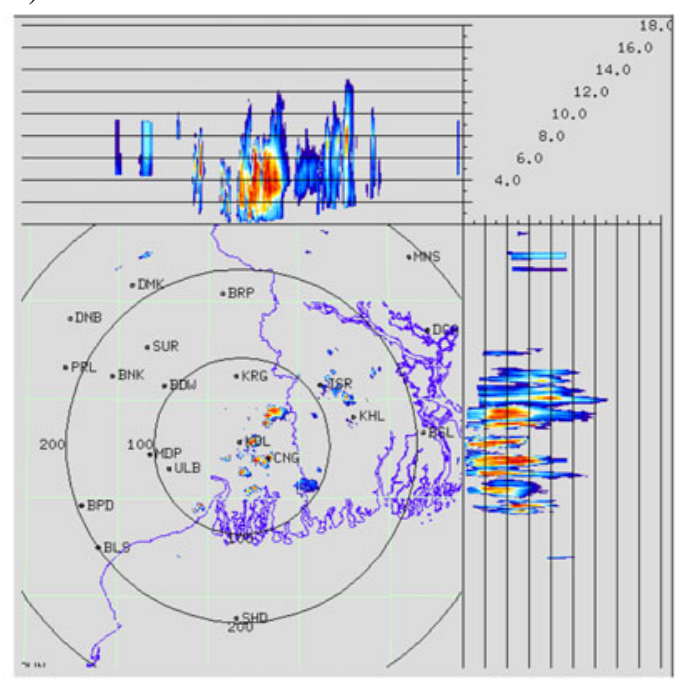

d) 1200 UTC

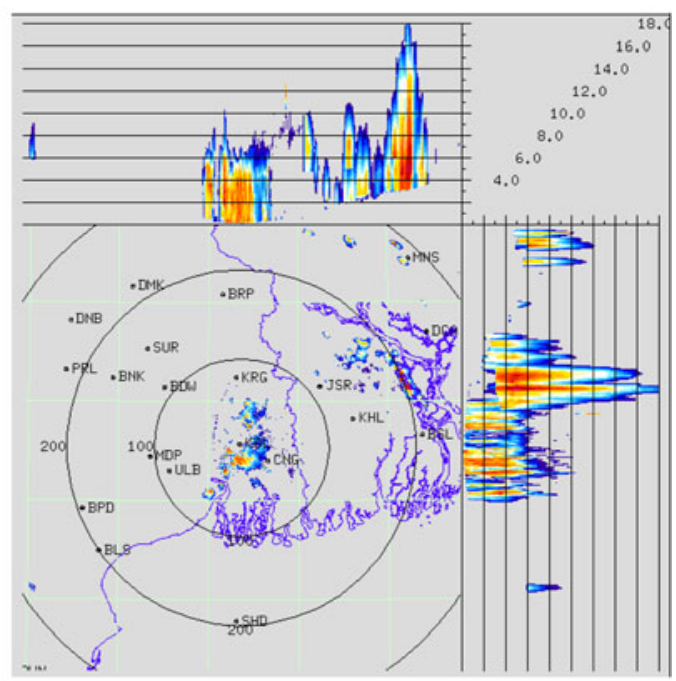

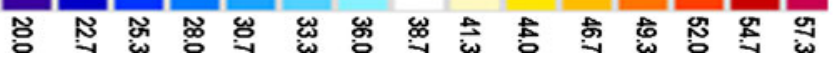

Figure 7. Kolkata DWR composite radar reflectivity imageries (dBZ) from 0900 to 1200 UTC on 20 May 2006. 
(IMD-19.6 mm, TRMM-21.1 mm, FERR $18.7 \mathrm{~mm}$ ). Verifying forecasts with statistical analysis measures how the values of the forecasts differ from the values of the observations. A statistical analysis based on Root Mean Square Error (RMSE), Mean Absolute Error (MAE) and Mean Error (ME) was performed for comparisons between the simulated and observed 24-h accumulated rainfall over the six meteorological stations and are given in table 5. From this statistical analysis, the interesting finding is that the RMSE, MAE and ME of the TRMM data with respect to the IMD observation is higher than NMM simulated rainfall with different microphysics schemes. TRMM has overestimated the rainfall amount for all six stations and the errors are very high. Huffman et al (2007) mentioned this inconsistency in their paper as TMPA has lower skill in correctly specifying moderate and light rainfall amounts on short time intervals, in common with other finescale estimators. FERR scheme has lesser errors as compared to WSM6 and THOM schemes. WSM6 scheme has the least accuracy than other two schemes. The comparison between forecast and observed precipitation fields, both in a statistical and in a deterministic (rainfall plot) approach, shows the NMM model with FERR scheme has well simulated the $24 \mathrm{~h}$ accumulated rainfall over east Indian region. The sensitivity of the surface precipitation illustrates that the microphysics scheme can significantly impact the accuracy of quantitative precipitation forecasts during the pre-monsoon season.

\subsubsection{Simulated radar reflectivity and cloud top, temperature}

DWR is being used worldwide for the study of various severe weather phenomena like thunderstorms, hailstorms, tornadoes and cyclones. Doppler radar has a great potential to enhance the capabilities of researchers and scientists to estimate the intensity of precipitation in the cloud on real time basis, apart from helping to keep a close watch on its movement (Chatterjee et al 2008). The DWR was
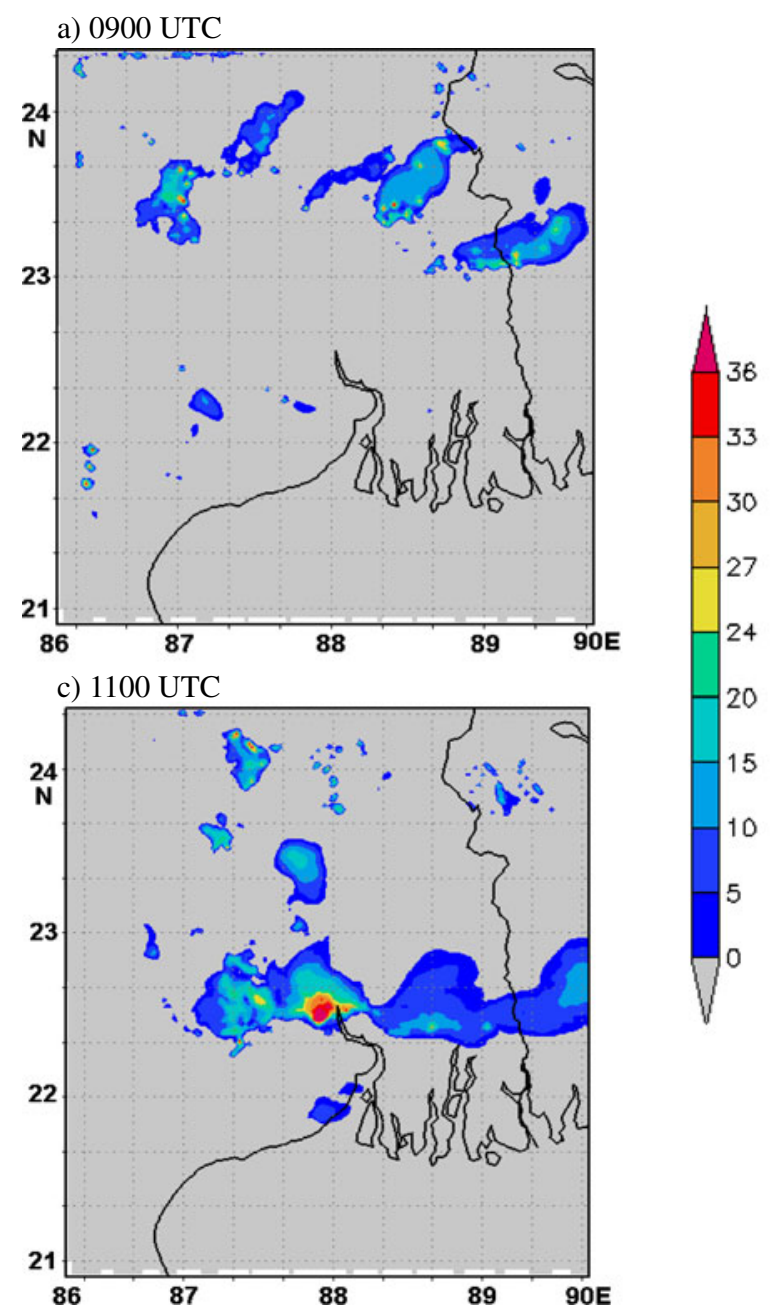

b) $1000 \mathrm{UTC}$

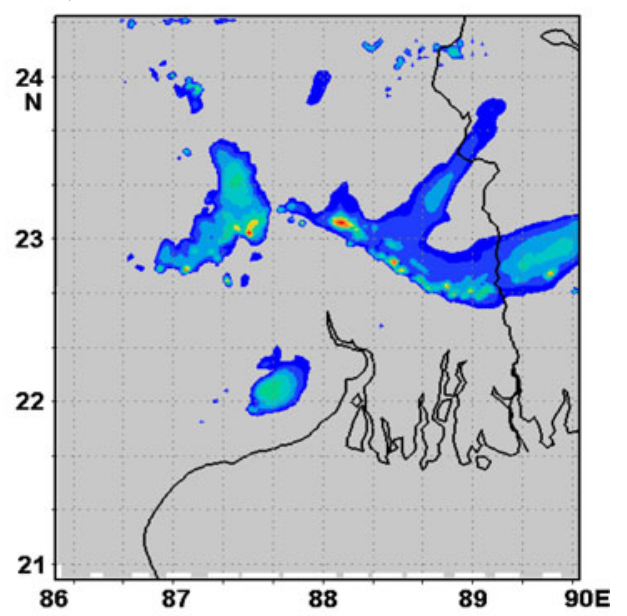

d) 1200 UTC

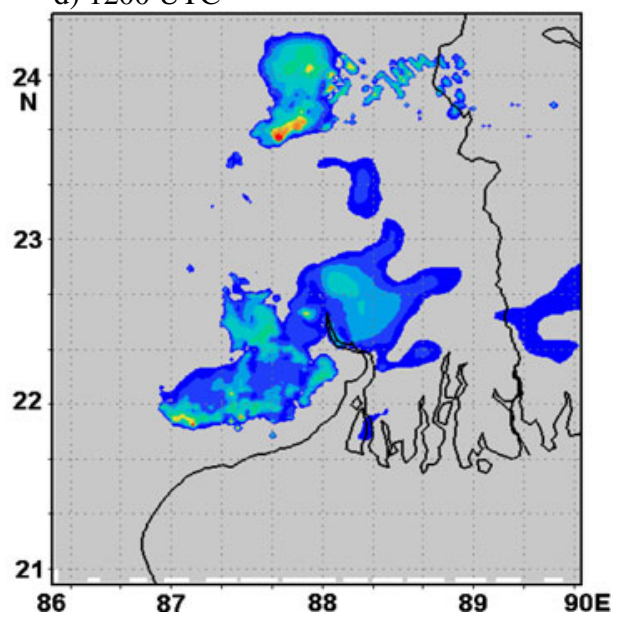

Figure 8. WRF-NMM simulated composite radar reflectivity (dBZ) pictures from 0900 to 1200 UTC on 20 May 2006. 
installed over Kolkata $\left(22.57^{\circ} \mathrm{N}, 88.35^{\circ} \mathrm{E}\right)$ in April 2002. The detailed description and principle of working of the radar has been given in Bhatnagar et al (2003).

The storm structure can be evaluated by comparing the modelled radar reflectivity to the observed radar reflectivity. In order to achieve that we have compared composite radar reflectivity (dBZ) calculated in different simulation times with observed one. Figure 3 shows the Kolkata DWR imageries for the thunderstorm event, which occurred on 15 May 2009. The analysis of these imageries reveals that a strong echo was developed near Purulia (PRL) at 1000 UTC, which intensified into north-south oriented squall line by 1100 UTC. This echo gradually moved southeastwards at 1200 UTC. This echo was passed over
Kolkata by 1300 UTC. The intensity of the squall was reduced thereafter and disappeared at 1500 UTC. The movements of this severe thunderstorm are from northwest to southeast as in the typical Nor'westers. NMM model simulated composite radar reflectivity with FERR scheme on 15 May 2009 from 1000 to 1300 UTC is shown in figure 4(a). By analyzing simulated reflectivity plots we can see that a strong echo developed northwest of Kolkata at 1000 UTC. This echo was moving towards Kolkata at 1100 UTC and over Kolkata at 1300 UTC as in the DWR imageries. The movement of squall line was well captured by FERR scheme. But the model has limited success for its intensity. The other microphysics schemes namely WSM6 (figure 4b) and THOM (figure 4c) also captured this squall line movement which was a) 0800 UTC

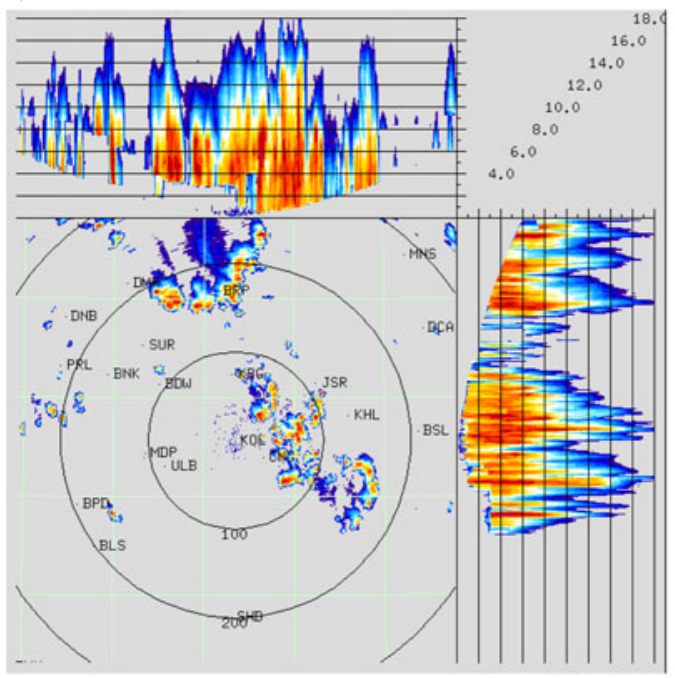

c) $1000 \mathrm{UTC}$

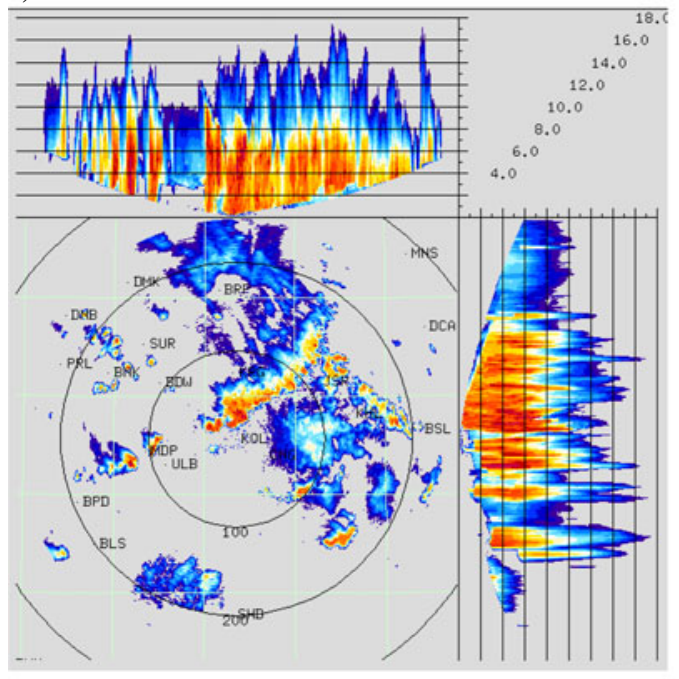

b) 0900 UTC

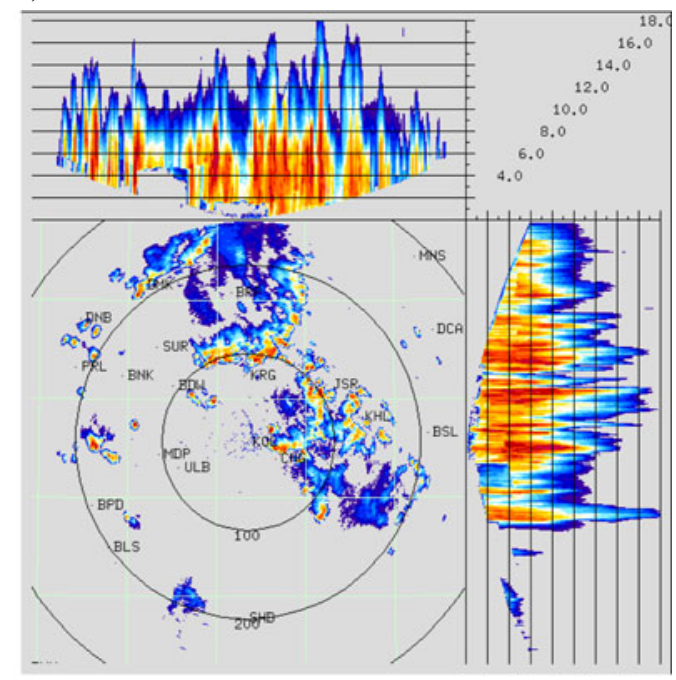

d) 1100 UTC

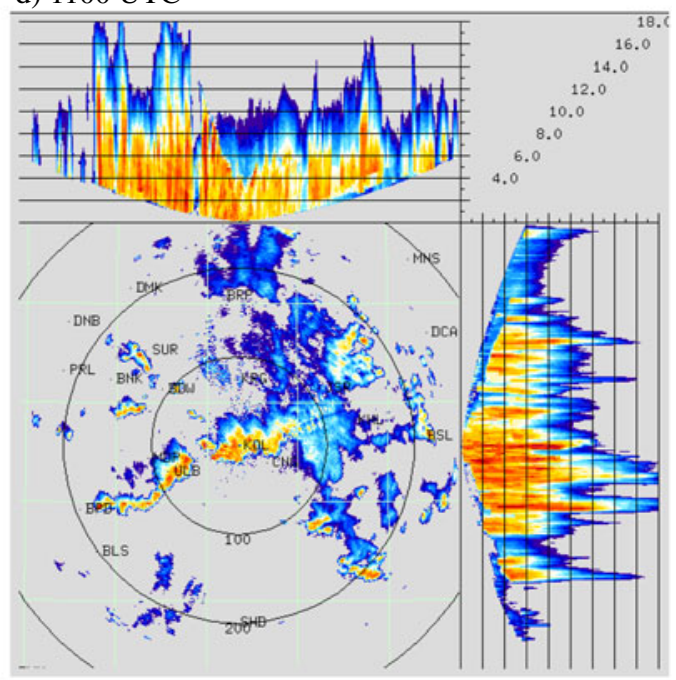

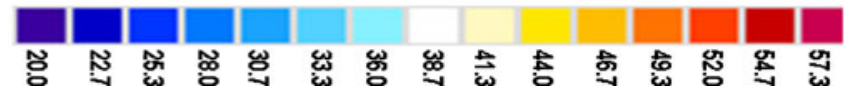

Figure 9. Kolkata DWR composite radar reflectivity (dBZ) imageries from 0800 to 1100 UTC on 21 May 2007. 
initiated northwest of Kolkata at 1000 UTC. As in the FERR scheme, WSM6 and THOM schemes produced less squall line intensity as compared to the DWR observations. From the analysis of the composite radar reflectivity for three microphysics schemes, we conclude that all three microphysics schemes have well simulated genesis, intensification and propagation of the severe thunderstorm as in the DWR radar reflectivity imageries, but failed to capture the magnitude of composite radar reflectivity as in observations.

The ability to accurately forecast cloudiness is necessary in the field of aviation. In recent years, brightness temperature and cloud top temperature derived from NWP model output have been used to demonstrate the advanced capabilities of these models for severe weather prediction (Otkin and Greenwald 2008). In this section, we have examined the ability of different combinations of cloud microphysics parameterization schemes implemented in the NMM model to realistically simulate the cloud top temperature (CTT) over West Bengal region.
The comparison of Kalpana satellite IR imageries with model simulated CTT are presented here. The satellite imageries (figure 5) of this thunderstorm case show that two convective cells developed over Bangladesh (northeast of Kolkata) and Jharkhand (northwest of Kolkata) at 1000 UTC. These cells expanded and merged over West Bengal by 1200 UTC, reached a maximum CTT of $-60^{\circ} \mathrm{C}$. This cell is more intensified at $1300 \mathrm{UTC}$, reached upto $-70^{\circ} \mathrm{C}$ and was dissipated by 1800 UTC. The NMM model simulated CTT (figure 6) with FERR schemes also shows both convective cell over northeast and northwest of Kolkata at 1000 UTC. These cells are merged over West Bengal at 1200 UTC as in the satellite imageries. The model simulated CTT reached upto $-70^{\circ} \mathrm{C}$ during this cloud formation and movement. The NMM model simulated CTT with WSM6 and THOM also show the same cloud cluster over West Bengal region as in the FERR scheme and observations (results not shown). The convection diagnosed by the cloud top temperature appears to be fairly representative of a) 0800 UTC

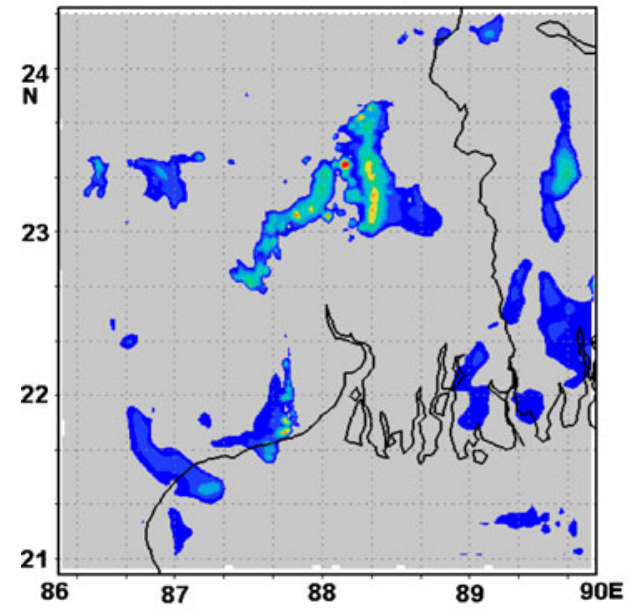

c) $1000 \mathrm{UTC}$

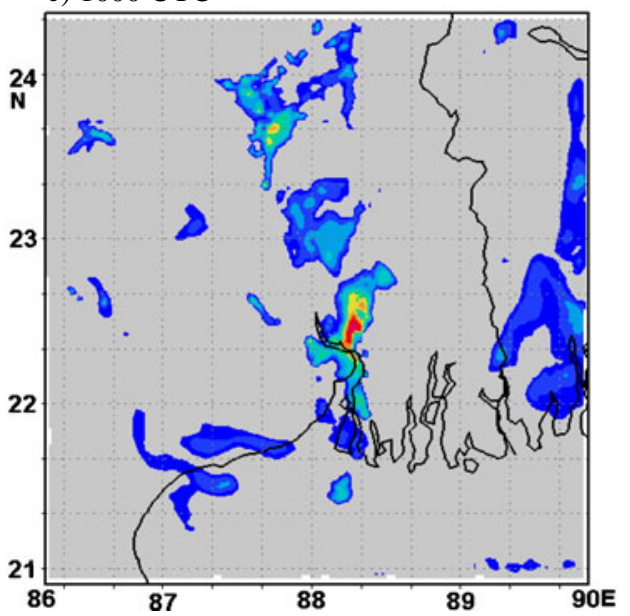

b) 0900 UTC

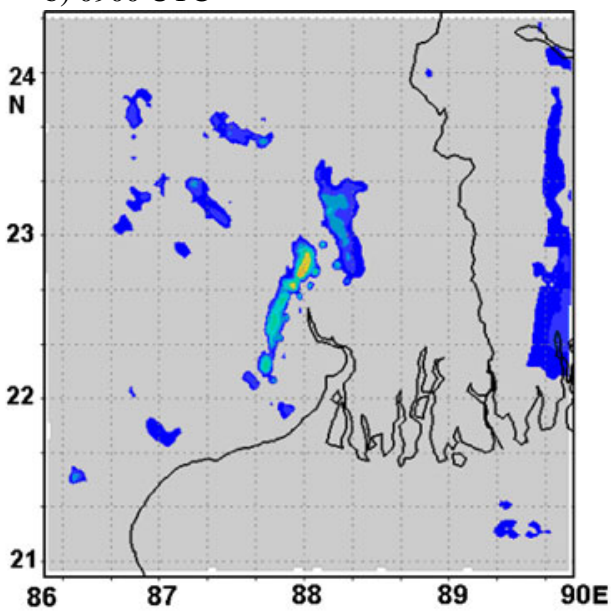

d) 1100 UTC

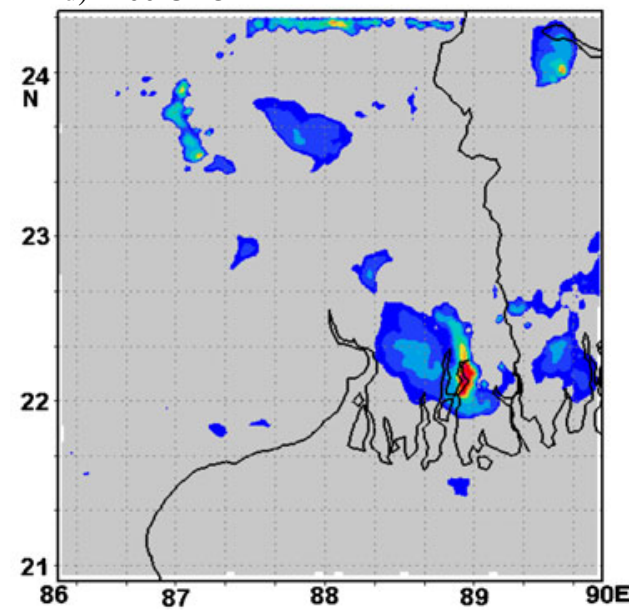

Figure 10. WRF-NMM simulated composite radar reflectivity (dBZ) pictures from 0800 to 1100 UTC on 21 May 2007. 
the structure and intensity observed in Kalpana satellite imageries.

\subsection{Observed and simulated radar reflectivity using Ferrier scheme}

In this section, the WRF-NMM model simulated composite radar reflectivity (dBZ) with FERR scheme has been compared with Kolkata DWR Product, Max (Z) (dBZ) for severe thunderstorm cases during 2006, 2007 and 2008. The analysis of the results of these experiments is to determine the usefulness of high resolution WRF-NMM model simulated radar reflectivity for severe thunderstorm events and assist future severe thunderstorm simulations over east and northeast Indian region.

a) 1000 UTC

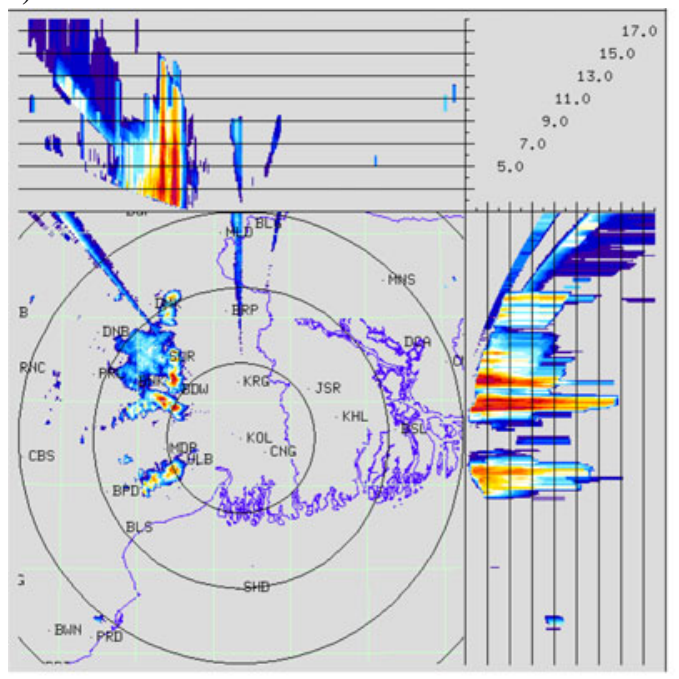

c) 1200 UTC

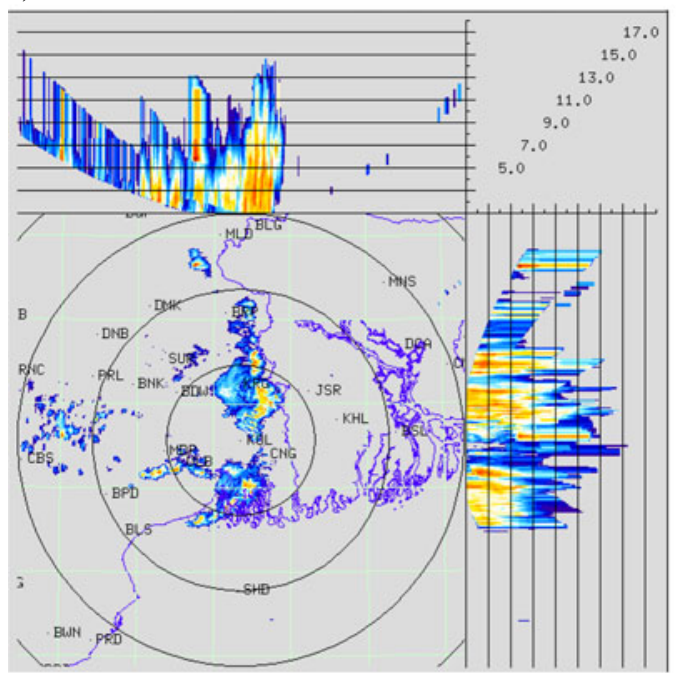

\subsubsection{Case 1: 20 May 2006}

A severe thunderstorm, which was reported on 20 May 2006 at 1200 UTC over Kolkata, is considered for the present study. This intense convective event produced $52 \mathrm{~mm}$ rainfall over Kolkata. The weather situation started with a squall passing Dum Dum airport on 20 May 2006 at 1100 UTC with a maximum speed of $19 \mathrm{~ms}^{-1}$ lasting for a few minutes. Kolkata DWR composite radar reflectivity imageries on 20 May 2006 from 0900 to 1200 UTC is shown in figure 7 . From the DWR products, one can see that scattered echoes which developed northeast of Kolkata (KOL) at 0900 UTC, moved towards Kolkata at 1000 UTC and intensified at 1100 UTC. This echo disappeared at 1300 UTC (Mohanty et al 2006). NMM model simulated composite radar reflectivity on 20 May 2006 from 0900

b) 1100 UTC

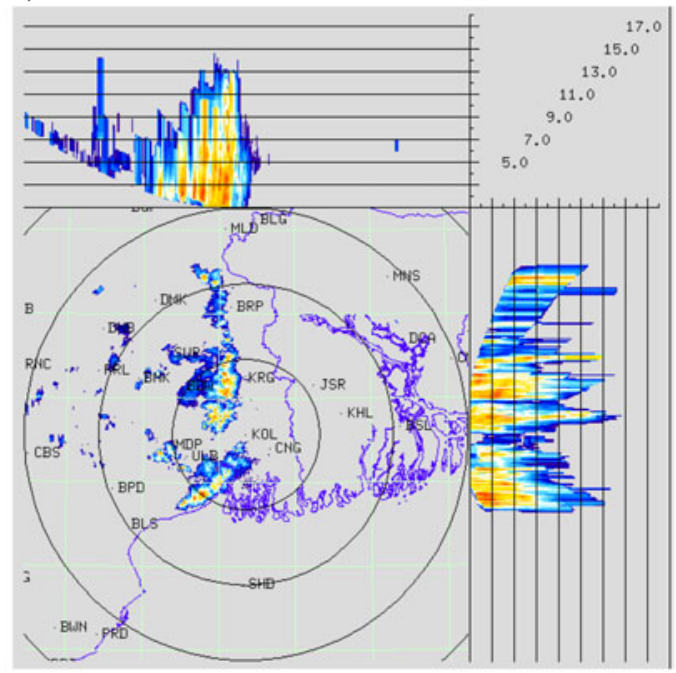

d) 1300 UTC

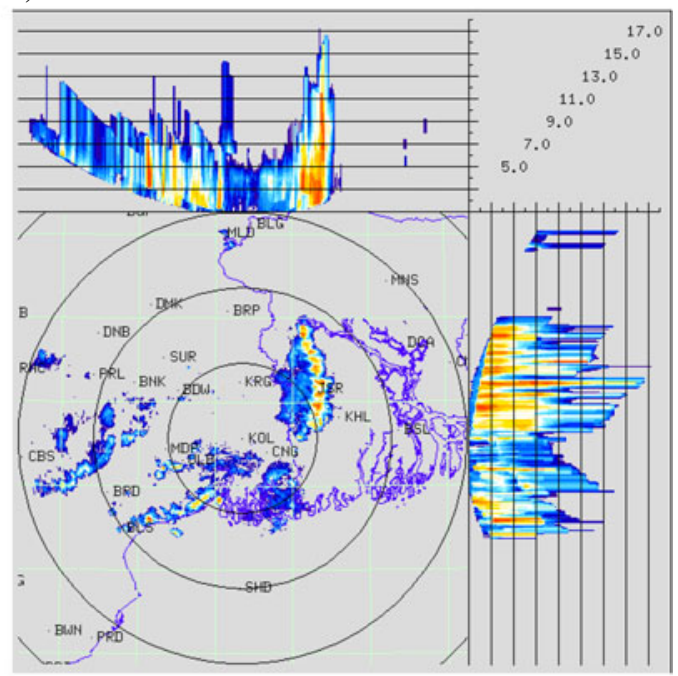

Figure 11. Kolkata DWR composite radar reflectivity (dBZ) imageries from 1000 to 1300 UTC on 20 March 2008. 
to 1200 UTC is shown in figure 8. By analyzing NMM model simulated composite radar reflectivity pictures, we can see that scattered echoes developed northeast of Kolkata at 0900 UTC. This echo was moving south westwards at 1000 UTC and intensified at 1100 UTC. This echo moved further in southwest direction at 1200 UTC. The NMM model simulated this squall movement by simulated composite radar reflectivity fields as observed by DWR imageries.

\subsubsection{Case 2: 21 May 2007}

Another severe thunderstorm occurred over Kolkata on 21 May 2007 at 1100 UTC is considered for the present study. A squall was reported over MO Kolkata at 1100 UTC from northwesterly direction with maximum speed of $19 \mathrm{~ms}^{-1}$ lasted for 1 minute. This convective event produced $20 \mathrm{~mm}$ rainfall over Kolkata. Kolkata DWR composite radar reflectivity imageries on 21 May 2007 from 0800 to 1100 UTC is shown in figure 9. By analyzing DWR imageries, we can see

a) 1000 UTC

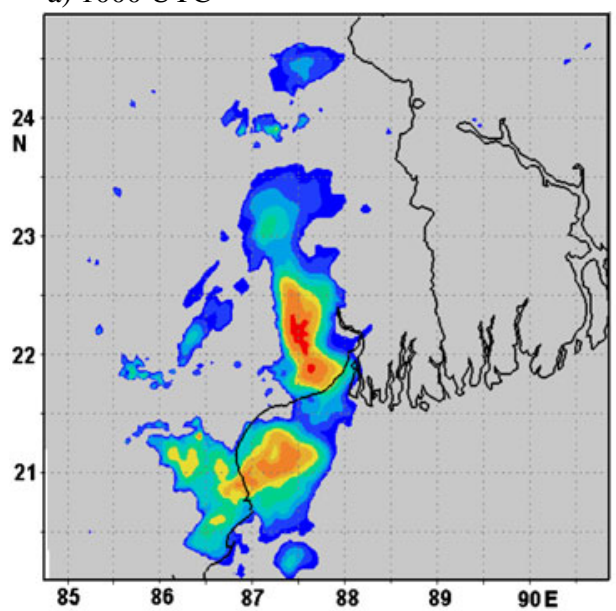

c) 1200 UTC

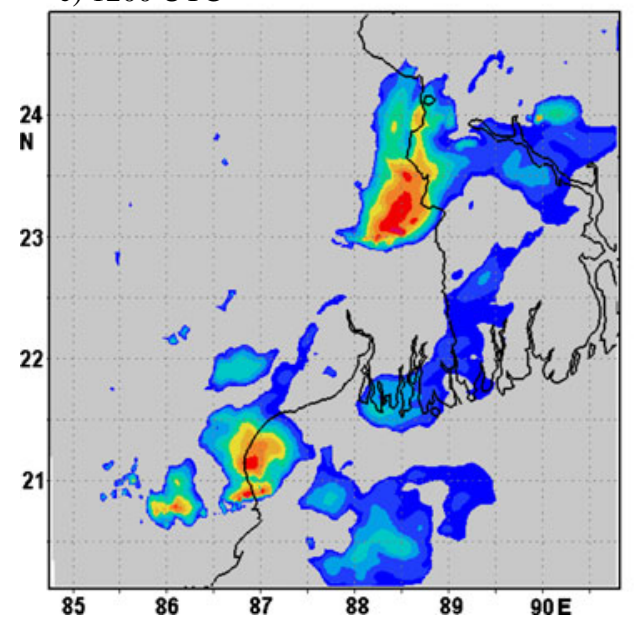

that scattered echoes are developed near Dumka (DMK) at 0800 UTC and moving south eastwards at 0900 UTC. This echo is intensified into a squall line (30 km north of Kolkata) at 1000 UTC. This squall line moved further in southeast direction (Mohanty et al 2007). NMM model simulated composite radar reflectivity on 21 May 2007 from 0800 to 1100 UTC is shown in figure 10. By analyzing NMM model simulated composite radar reflectivity pictures, we can see that scattered echoes developed north-west of Kolkata at 0800 UTC. This echo was moving south eastwards at 0900 UTC and intensified at 1000 UTC. This echo moved further in southeast direction and disappeared over sea. The model simulated this thunderstorm movement with simulated composite radar reflectivity fields.

\subsubsection{Case 3: 20 March 2008}

Kolkata DWR composite radar reflectivity imageries on 20 March 2008 from 1000 to 1300 UTC are shown in figure 11. Analysis of DWR

b) $1100 \mathrm{UTC}$

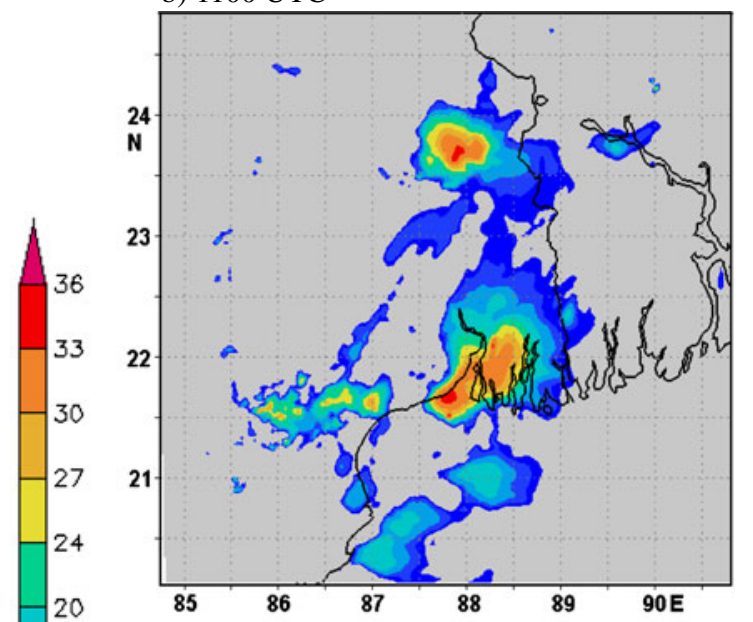

d) 1300 UTC

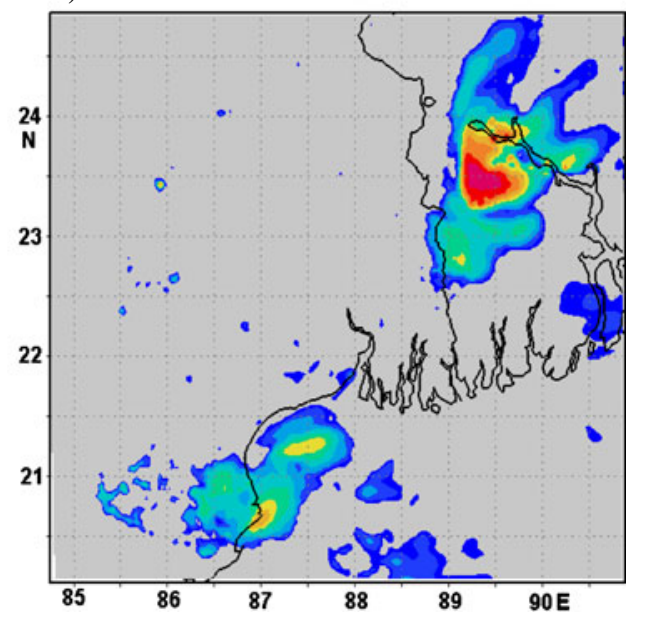

Figure 12. WRF-NMM simulated composite radar reflectivity (dBZ) pictures from 1000 to 1300 UTC on 20 March 2008. 
imageries reveal that scattered echoes are developed near Bhardhaman (BDW) (northwest of Krishnagar (KRG)) at 1000 UTC. This echo is intensified into a squall line and moving eastwards at 1100 UTC. This squall line is passed over KRG at 1200 UTC. This echo moved further in eastward direction at 1300 UTC. NMM model simulated composite radar reflectivity on 20 March 2008 from 1000 to 1300 UTC is shown in figure 12. By analyzing NMM model simulated composite radar reflectivity pictures, we can see that scattered echoes are developed west of KRG at 1000 UTC. This echo is moved eastwards at 1100 UTC. This squall line is passed over KRG at 1200 UTC as in the DWR pictures. This echo moved further in eastward direction at 1300 UTC. In this case also, the NMM model was able to capture this squall line movement by simulated composite radar reflectivity fields as observed by DWR imageries.

\subsubsection{Case 4: 8 May 2008}

Kolkata DWR composite radar reflectivity imageries on 8 May 2008 from 1100 to 1400 UTC is shown in figure 13. A squall developed near Bankura (BNK) at 1100 UTC moved southeastwards at 1200 UTC. This squall line is passed over Kolkata (KOL) at 1400 UTC and moved further in southeast direction. NMM model simulated composite radar reflectivity on 8 May 2008 from 1100 to 1400 UTC is shown in figure 14. By analyzing NMM model simulated composite radar reflectivity pictures, we can see that a squall line a) $1100 \mathrm{UTC}$

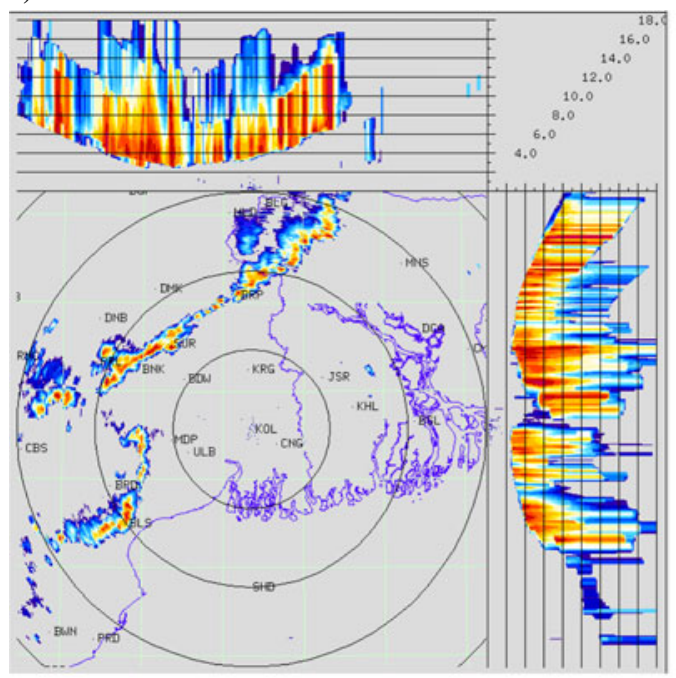

c) $1300 \mathrm{UTC}$

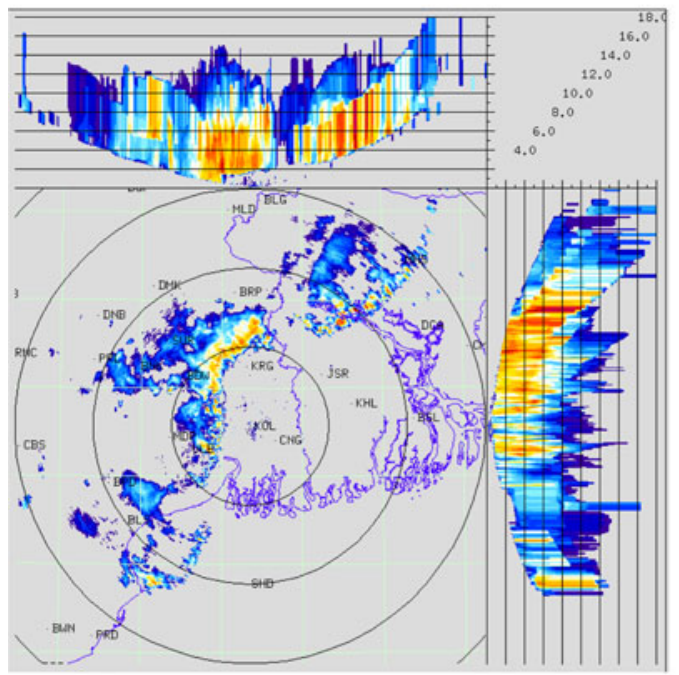

b) 1200 UTC

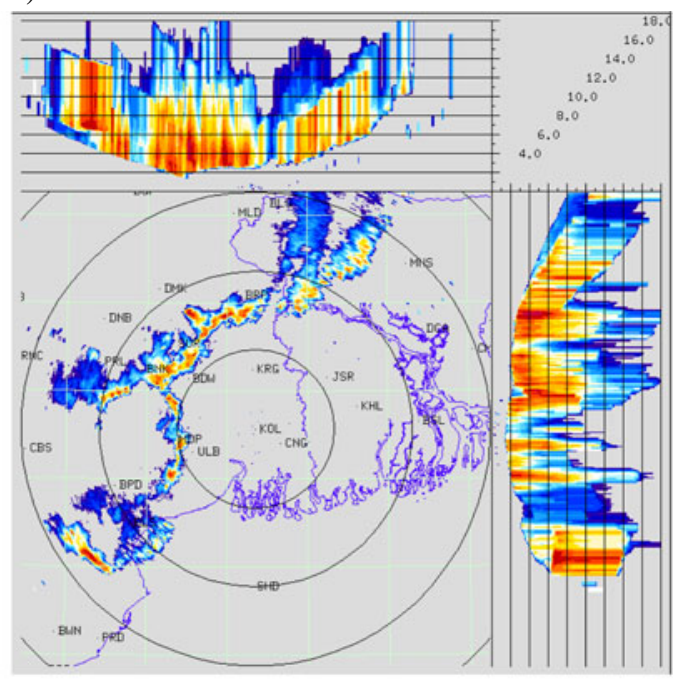

d) 1400 UTC

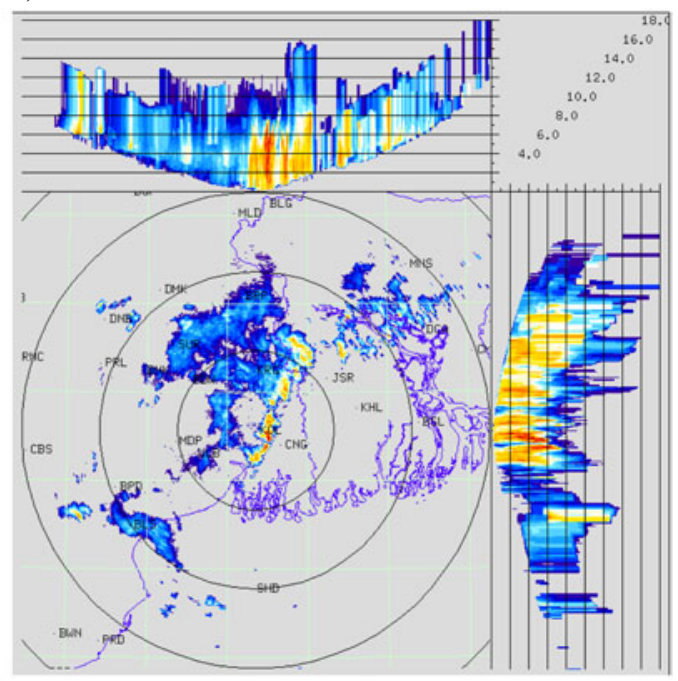

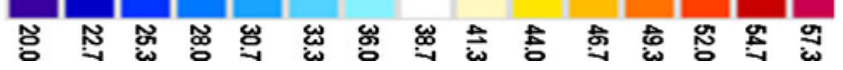

Figure 13. Kolkata DWR composite radar reflectivity (dBZ) imageries from 1100 to 1400 UTC on 8 May 2008. 
a) 1100 UTC

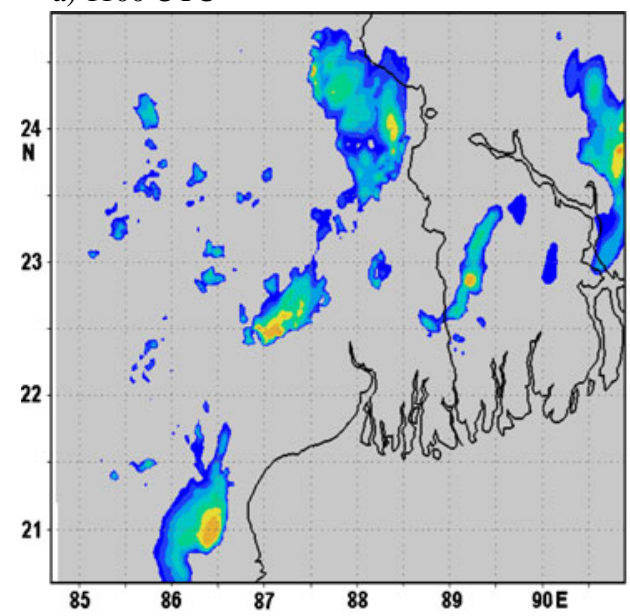

c) 1300 UTC

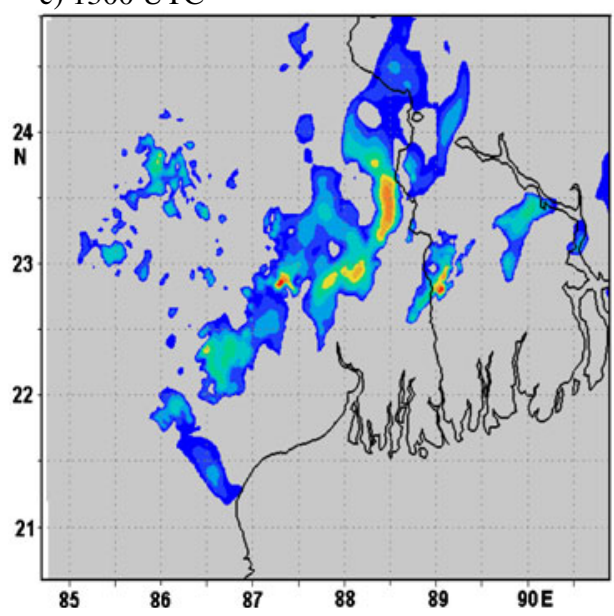

b) 1200 UTC

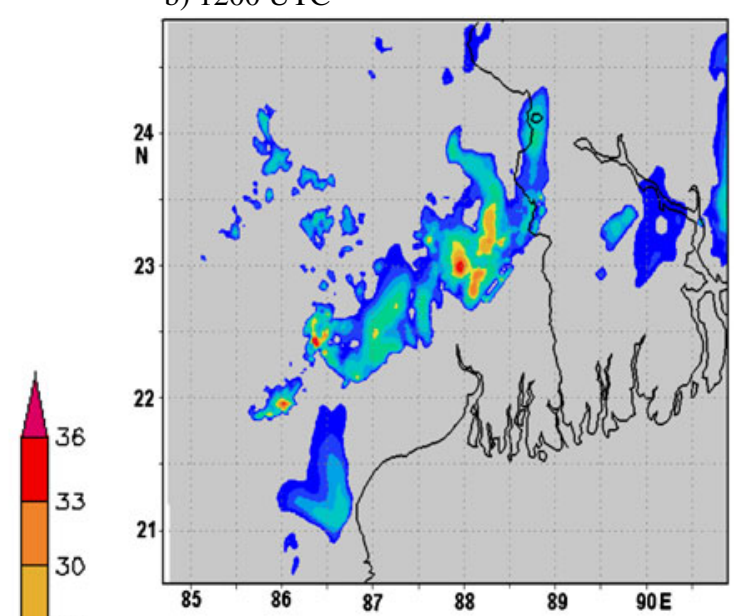

d) 1400 UTC

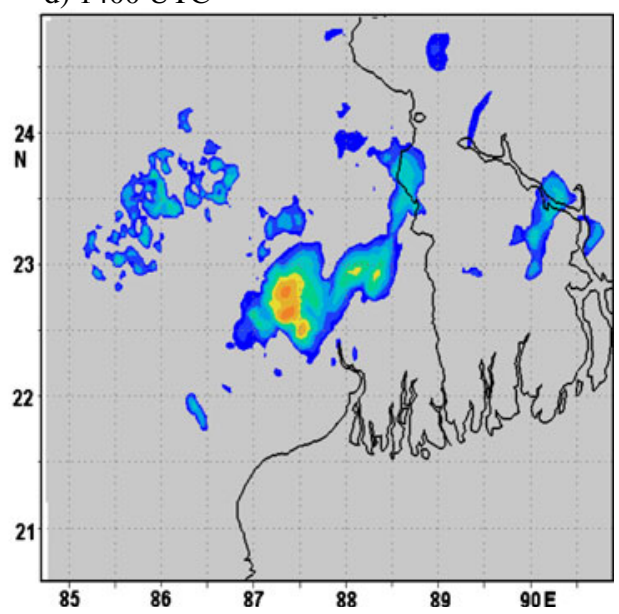

Figure 14. WRF-NMM simulated composite radar reflectivity (dBZ) pictures from 1100 to 1400 UTC on 8 May 2008.

is developed northwest of Kolkata at 1100 UTC. This echo is moved south eastwards at 1200 UTC. This echo passed over Kolkata at 1400 UTC and moved further in southeast direction. The NMM model has reasonably well simulated this squall line movement by simulated composite radar reflectivity fields as observed by DWR imageries.

Simulated radar reflectivity is an important part of the fidelity of the model cloud and precipitation microphysics forecast, since it is derived directly from the hydrometeor mixing ratios. Any biases in those mixing ratios will be reflected in the simulated reflectivity field. Furthermore, a particular challenge in trying to produce a simulated reflectivity product is the diameter-to-the-sixthpower dependence of equivalent reflectivity factor. This dependence renders reflectivity highly sensitive to the largest precipitation particles present, and thus renders simulated reflectivity highly sensitive not only to the precipitation mixing ratios, but to assumptions about the precipitation size distributions. It is conceivable that a model could be performing well in terms of precipitation forecast, but producing unrealistic reflectivity fields due to poor representation of the particle size distributions (Koch et al 2005). From the present analysis of the simulated composite radar reflectivity, we conclude that model has reasonably well simulated genesis, intensification and propagation of the five severe thunderstorms during 2006, 2007, 2008 and 2009 pre-monsoon season over east Indian region as in the DWR radar reflectivity imageries, but failed to capture the intensity as in observations.

\section{Conclusions}

In the present study, we have used a high resolution $(3 \mathrm{~km})$ WRF-NMM model to simulate severe thunderstorm events over West Bengal (east India) region that occurred during pre-monsoon seasons of 2006, 2007, 2008 and 2009. The present study was taken up to diagnose whether the model is 
able to simulate the thunderstorm events over this region. Sensitivity experiments have been conducted for a severe thunderstorm event on 15 May 2009 with three microphysical schemes namely Ferrier (FERR), WRF Single Moment 6 class (WSM6) and Thomson scheme (THOM) to examine the sensitivity of the simulations to different cloud microphysics. In all experiments, the setups were identical except for the use of different microphysics schemes. Hence differences in the simulation results may be attributed to the sensitivity of the microphysics schemes.

Examination of the model simulated stability indices such as CAPE, LI, KI and TTI with different microphysics schemes between 1000 and 1300 UTC of 15 May 2009, clearly indicated that NMM model with FERR scheme has well captured the instability of the atmosphere for the occurrence of a severe thunderstorm. The model simulated thermodynamic structure over Kolkata was conducive for a thunderstorm occurrence. CAPE, LI and TTI are well simulated by WSM6 and THOM microphysical schemes also. They are failed to reproduce an accurate value of KI index.

The model simulated surface precipitation with three microphysics schemes are analyzed and compared to the available surface observations and satellite derived precipitation data in order to identify the microphysics scheme that provide the best representation of the spatio-temporal variability of precipitation in severe thunderstorm conditions. The best results are produced by FERR microphysics scheme, which are the default schemes of the well-known and reliable ETA and WRF-NMM models. Similarly, good results are produced by THOM microphysics scheme. On the other hand, the worst results (with mean absolute error up to about $16.4 \mathrm{~mm}$ ) appear when WSM6 scheme is used.

From the model simulated spatial plots of composite radar reflectivity with three microphysics schemes, we can see that in all three cases, a thunder squall is initiated northwest of Kolkata, gradually moving towards Kolkata as in DWR imageries. The NMM model with all microphysical schemes has reasonably well simulated the movement of the severe thunderstorm of 15 May 2009 as in the DWR imageries. But the model has limited success for its intensity. The model simulated cloud top temperature appears to be fairly representative of the structure and intensity observed in satellite imageries. In the future, additional analysis will be undertaken for this case to explore each microphysical scheme in detail to understand why the Ferrier scheme did the better job with the severe thunderstorm over east Indian region.

We have also compared the simulated radar reflectivity fields from WRF-NMM model using
FERR microphysics scheme with Kolkata DWR imageries for another four severe thunderstorms that occurred during pre-monsoon seasons of 2006 , 2007 and 2008. From the analysis of the composite radar reflectivity, we conclude that model has reasonably well simulated genesis, intensification and propagation of the severe thunderstorms as in the DWR imageries, but failed to capture the intensity as in observations. The results of these analyses demonstrated the capability of high resolution WRF-NMM model in simulation of severe thunderstorm events and determined that the $3 \mathrm{~km}$ model improve upon current abilities when it comes to simulating severe thunderstorms over east and northeast Indian region.

\section{Acknowledgements}

The authors would like to express their sincere gratitude to the Department of Science and Technology for providing financial support. Thanks are also due to the data providers specially Dr Pradhan, India Meteorological Department (IMD), Kolkata. The TRMM images and data used in this study were acquired using the GES-DISC Interactive Online Visualization and analysis Infrastructure (Giovanni) as part of the NASA's Goddard Earth Sciences (GES) Data and Information Services Center (DISC). They are also thankful to the two anonymous reviewers for their constructive comments and suggestions which improved the quality of the paper.

\section{References}

Air Weather Service Technical Report 79/006 1990 The use of the skew T, Log P diagram in analysis and forecasting; Air Weather Service, Scott AFB, Illinois.

Bhatnagar A K, Rajesh Rao P, Kalyanasundaram S, Thampi S B, Suresh R and Gupta J P 2003 Doppler radar-A detecting tool and measuring instrument in meteorology; Curr. Sci. 85(3) 256-264.

Chatterjee P, Pradhan D and De U K 2008 Simulation of hailstorm event using mesoscale model MM5 with modified cloud microphysics scheme; Annales Geophysicae 26 $3545-3555$.

Das Someshwar 1999 Suggested observational network for simulation of cloud processes during the Indian Ocean Experiment (INDOEX); Curr. Sci. $\mathbf{7 6 ( 7 )}$ 912-915.

Ferrier B S, Lin Y, Black T, Rogers E and Di Mego G 2002 Implementation of a new grid-scale cloud and precipitation scheme in the NCEP Eta model; Preprints, 15th Conference on Numerical Weather Prediction, San Antonio, TX, Amer. Meteor. Soc., pp. 280-283.

Hong S Y, Dudhia J and Chen S H 2004 A revised approach to ice microphysical processes for the bulk parameterization of clouds and precipitation; Mon. Weather Rev. 132 103-120.

Huffman G J et al 2007 The TRMM multi-satellite precipitation analysis: Quasi-global, multi-year, combined sensor 
precipitation estimates at fine scales; J. Hydrometeorol. 8 38-55.

Janjic Z I 1984 Non-linear advection schemes and energy cascade on semi-staggered grids; Mon. Weather Rev. 112 $1234-1245$.

Janjic Z I 2003 A nonhydrostatic model based on a new approach; Meteorol. Atmos. Phys. 82 271-285.

Johns R H and Doswell C A 1992 Severe local storms forecasting; Weather Forecast. 7 588-612.

Kain J S, Weiss S J, Levit J J, Baldwin M E and Bright D R 2006 Examination of convection-allowing configurations of the WRF model for the prediction of severe convective weather: The SPC/NSSL Spring Program 2004; Weather Forecast. 21(2) 167.

Koch S E, Ferrier B, Stolinga M, Szoke E, Weiss S J and Kain J S 2005 The use of simulated radar reflectivity fields in the diagnosis of mesoscale phenomena from highresolution WRF model forecasts; Preprints, 11th Conference on Mesoscale Processes, Albuquerque, NM, Amer. Meteor. Soc., CD-ROM, J4J.7.

Litta A J, Chakrapani B and Mohankumar V 2007 Mesoscale simulation of an extreme rainfall event over Mumbai, India, using a high-resolution MM5 model; Meteorol. Appl. 14(3) 291-295.

Litta A J and Mohanty U C 2008 Simulation of a severe thunderstorm event during the field experiment of STORM programme 2006, using WRF-NMM model; Curr. Sci. 95(2) 204-215.

Litta A J, Mohanty U C and Bhan S C 2010 Numerical simulation of a tornado over Ludhiana (India) using WRF-NMM model; Meteorol. Appl. 17 64-75.

Liu C and Moncrieff M W 2007 Sensitivity of cloudresolving simulations of warm-season convection to cloud microphysics parameterizations; Mon. Weather Rev. 135 2854-2868.

Miller R C 1972 Notes on analysis and severe storm forecasting procedures of the Air Force Global Weather Central AWS TR 200 (revised) Air Weather Service Scott Air Force Base, Illinois.

Mohanty U C, Mandal M and Raman S 2004 Simulation of Orissa Super Cyclone (1999) using PSU/NCAR Mesoscale model; Natural Hazards 31 373-390.

Mohanty U C, Sikka D R, Madan O P and Pareek R S et al 2006 Weather Summary Pilot Experiment of Severe Thunderstorms-Observational and Regional Modeling (STORM) Programme - 2006.

Mohanty U C, Sikka D R, Madan O P and Pareek R S et al 2007 Weather Summary Pilot Experiment of Severe Thunderstorms - Observational and Regional Modeling (STORM) Programme - 2007.

Mohanty U C, Sikka D R, Madan O P, Kiran Prasad S, Litta A J et al 2009 Weather Summary Pilot Experiment of Severe Thunderstorms - Observational and Regional Modeling (STORM) Programme - 2009.

Otkin J A, Huang H L and Seifert A 2006 A comparison of microphysical schemes in the WRF model during a severe weather event; Preprints, 7th Annual WRF User's Workshop, Boulder, CO.

Otkin J A and Greenwald T J 2008 Comparison of WRF model-simulated and MODIS-derived cloud data; Mon. Weather Rev. 136 1957-1970.

Rajeevan M, Kesarkar A, Thampi S B, Rao T N, Radhakrishna B and Rajasekhar M 2010 Sensitivity of WRF cloud microphysics to simulations of severe thunderstorm event over Southeast India; Ann. Geophys. 28 603-619.

Rao Y V R, Hatwar H R, Salah A K and Sudhakar Y 2007 An experiment using the high resolution eta and WRF models to forecast heavy precipitation over India; Pure Appl. Geophys. 164(8-9) 1593-1615.

Science Plan 2005 Severe Thunderstorms - Observations \& Regional Modeling (STROM) Programme; Department of Science \& Technology, Government of India, New Delhi, December 2005.

Sen Roy S, Lakshmanan V, Roy Bhowmik S K and Thampi S B 2010 Doppler weather radar based nowcasting of cyclone Ogni; J. Earth Syst. Sci. 119 183-199.

Srivastava K, Roy Bhowmik S K, Sen Roy S, Thampi S B and Reddy Y K 2010 Simulation of high impact convective events over Indian region by ARPS model with assimilation of Doppler weather radar radial velocity and reflectivity; Atmosfera 23 53-73.

Stensrud D J, Bao J W and Warner T T 2000 Using initial condition and model physics perturbations in short-range ensemble simulations of mesoscale convective systems; Mon. Weather Rev. 128 2077-2107.

Szoke E J, Koch S E, Barjenbruch D and Wesley D A 2007 Evaluation of the NCEP WRF NMM and ARW models for some recent high-impact weather events; 22nd Conference on Weather Analysis and Forecasting; 18th Conference on Numerical Weather Prediction, Park City, UT.

Thompson G, Rasmussen R M and Manning K 2004 Explicit forecasts of winter precipitation using an improved bulk microphysics scheme. Part I: Description and sensitivity analysis; Mon. Weather Rev. 132 519-542.

Vaidya S S 2007 Simulation of weather systems over Indian region using mesoscale models; Meteorol. Atmos. Phys. 95 15-26.

Wandishin M S, Mullen S L, Stensrud D J and Brooks H E 2001 Evaluation of a short-range multimodel ensemble system; Mon. Weather Rev. 129 729-747.

Wang Wei and Seaman N L 1997 A comparison study of convective parameterization schemes in a mesoscale model; Mon. Weather Rev. 125 252-278. 